\title{
VGLUT3 (Vesicular Glutamate Transporter Type 3) Contribution to the Regulation of Serotonergic Transmission and Anxiety
}

\author{
Bénédicte Amilhon, ${ }^{1,2,3 *}$ Ève Lepicard, ${ }^{1,2,3 *}$ Thibault Renoir, ${ }^{4}$ Raymond Mongeau, ${ }^{4 *}$ Daniela Popa, ${ }^{5 *}$ Odile Poirel, ${ }^{1,2,3}$ \\ Stéphanie Miot, ${ }^{1,2,3,6}$ Christelle Gras, ${ }^{1,2,3}$ Alain M. Gardier, ${ }^{5}$ Jorge Gallego, ${ }^{6}$ Michel Hamon, ${ }^{4}$ Laurence Lanfumey, ${ }^{4}$ \\ Bruno Gasnier, ${ }^{7}$ Bruno Giros, ${ }^{1,2,3,8}$ and Salah El Mestikawy ${ }^{1,2,3,8}$ \\ ${ }^{1}$ Inserm, U952, Université Pierre et Marie Curie (UPMC), 75005 Paris, France, ${ }^{2}$ Centre National de la Recherche Scientifique (CNRS) Unité Mixte de \\ Recherche 7224, 75005 Paris, France, ${ }^{3}$ UPMC Paris 06, Pathophysiology of Central Nervous System Disorders, 75005 Paris, France, ${ }^{4}$ Inserm, U677, \\ Neuropsychopharmacology, 75013 Paris, France, ${ }^{5}$ Laboratoire de Neuropharmacologie, Université Paris-Sud, EA 3544, Faculté de Pharmacie, Chatenay- \\ Malabry Cedex F-92296, France, ${ }^{6}$ Inserm, U676, Hôpital Robert Debré, 75019 Paris, France, ${ }^{7}$ Institut de Biologie Physico-Chimique, CNRS, Université Paris \\ Descartes, 75005 Paris, France, and ${ }^{8}$ Douglas Hospital Research Center, Department of Psychiatry, McGill University, Montreal, H4H 1R3 Quebec, Canada
}

Three different subtypes of $\mathrm{H}^{+}$-dependent carriers (named VGLUT1-3) concentrate glutamate into synaptic vesicles before its exocytotic release. Neurons using other neurotransmitter than glutamate (such as cholinergic striatal interneurons and 5-HT neurons) express VGLUT3. It was recently reported that VGLUT3 increases acetylcholine vesicular filling, thereby, stimulating cholinergic transmission. This new regulatory mechanism is herein designated as vesicular-filling synergy (or vesicular synergy). In the present report, we found that deletion of VGLUT3 increased several anxiety-related behaviors in adult and in newborn mice as early as $8 \mathrm{~d}$ after birth. This precocious involvement of a vesicular glutamate transporter in anxiety led us to examine the underlying functional implications of VGLUT3 in 5-HT neurons. On one hand, VGLUT3 deletion caused a significant decrease of 5- $\mathrm{HT}_{1 \mathrm{~A}}$-mediated neurotransmission in raphe nuclei. On the other hand, VGLUT3 positively modulated 5-HT transmission of a specific subset of 5-HT terminals from the hippocampus and the cerebral cortex. VGLUT3- and VMAT2-positive serotonergic fibers show little or no 5-HT reuptake transporter. These results unravel the existence of a novel subset of 5-HT terminals in limbic areas that might play a crucial role in anxiety-like behaviors. In summary, VGLUT3 accelerates 5-HT transmission at the level of specific 5-HT terminals and can exert an inhibitory control at the raphe level. Furthermore, our results suggest that the loss of VGLUT3 expression leads to anxiety-associated behaviors and should be considered as a potential new target for the treatment of this disorder.

\section{Introduction}

Serotonin (5-HT)-producing neurons located in the dorsal and medial raphe nuclei (DRN and MRN, respectively) provide dense 5-HT innervations throughout the entire forebrain and brainstem (Dahlstroem and Fuxe, 1964). Despite their relatively small number ( $\sim 12,000$ in the rodent brain) (Ishimura et al., 1988), these neurons exert a tonic modulatory influence on a wide range of neuronal and physiological processes and play key trophic functions in the assembly of brain circuitries (for review, see

Received Oct. 19, 2009; revised Dec. 9, 2009; accepted Dec. 25, 2009.

This work was supported by grants from Inserm, Agence Nationale pour la Recherche, and France Canada Research Fund. B.A. was supported by a fellowship from Fondation pour la Recherche Médicale, S.M. by École de I'Inserm-Lilliane Bettencourt, and E.L. by Fédération pour la Recherche sur le Cerveau and France Alzheimer. We are grateful to Dr. Virginie Georget and Richard Schwartzmann (Plateforme imagerie cellulaire, Institut Féderatif de Recherche de Biologie Intégrative, IFR-83) for their assistance with confocal microscopy, Phillipe Mailly for image analysis, Franck Louis for excellent technical assistance, and Boris Matrot and Yann Rotrou for ultrasonic signal processing.

*B.A. and E.L. as well as R.M. and D.P. contributed equally to this work.

Correspondence should be addressed to Dr. Salah El Mestikawy, Inserm U952, CNRS UMR 7224, Université Pierre et Marie Curie, 75005 Paris, France. E-mail: salah.elmestikawy@snv.jussieu.fr.

DOI:10.1523/JNEUROSCI.5196-09.2010

Copyright $\odot 2010$ the authors $\quad 0270-6474 / 10 / 302198-13 \$ 15.00 / 0$
Gaspar et al., 2003). Modifications of central 5-HT activity are consistently associated with the treatment and, possibly, the etiology of affective disorders: anxiety, depression, bipolar affective disorders, obsessive-compulsive disorders (Lesch et al., 1996; Owens and Nemeroff, 1998; Leonardo and Hen, 2008). Numerous attempts have been made to model 5-HT system dysfunctions in mice. Knock-out $(\mathrm{KO})$ mice lacking key enzymes (tryptophan hydroxylase, monoamine oxidase $\mathrm{A}$ ), receptors $\left(5-\mathrm{HT}_{1 \mathrm{~A}}, 5-\mathrm{HT}_{1 \mathrm{~B}}\right.$, or 5- $\mathrm{HT}_{2 \mathrm{~A}}$ ) or transporters [5-HT reuptake transporter (SERT) or vesicular monoamine transporter 2 (VMAT2)] of the 5-HT system have been developed (for review, see Gingrich and Hen, 2001). Studying these models has brought support to the notion of 5-HT central involvement in mood and anxiety disorders.

Recently, the surprising observation was made that a majority of central 5-HT neurons express the vesicular glutamate transporter VGLUT3 (Fremeau et al., 2002; Gras et al., 2002; Schäfer et al., 2002; Takamori et al., 2002). The role of this unconventional transporter remains unexplored. As demonstrated in the auditory system, VGLUT3 is involved in fast excitatory glutamatergic transmission similarly to the other two subtypes of vesicular glutamate transporter, VGLUT1 and VGLUT2 (Ruel et al., 2008; 
Seal et al., 2008). Thus, VGLUT3 clearly fulfils the function of an actual vesicular glutamatergic transporter, with its expression conferring to neurons the ability to release glutamate. Moreover, in addition to this expected function, VGLUT3 enhances striatal cholinergic neurotransmission at the presynaptic level (Gras et al., 2008). In the striatum, due to the presence of VGLUT3, the vesicular amount of acetylcholine as well as cholinergic transmission are both increased relatively to other cholinergic pathways. This new presynaptic regulatory mechanism dynamically regulates cholinergic striatal transmission. Consequently, at least two roles can be inferred for VGLUT3 in 5-HT neurons: (1) modulation of local neurotransmission at the vesicular level through the "primary" transmitter and (2) fast excitatory transmission through the release of glutamate. Previous studies established that (1) VGLUT3 transcript is massively expressed in the soma of 5-HT neurons from early embryonic life to adulthood (Gras et al., 2002; Cheng et al., 2003); and (2) the transporter itself is detected in discrete subsets of serotonergic fibers (Hioki et al., 2004; Somogyi et al., 2004; Shutoh et al., 2008). However, both the distribution and the function of VGLUT3 in the 5-HT system await further investigations.

To explore these points, we characterized a Vglut $3^{-1-}$ mouse line with anatomical, biochemical, electrophysiological and behavioral paradigms. We report that VGLUT3 deletion decreased 5-HT tone in projection areas such as the hippocampus and, unexpectedly, decreased 5- $\mathrm{HT}_{1 \mathrm{~A}}$ autoreceptors-mediated transmission in the raphe. VGLUT3 knock-out mice also displayed a noticeable increase in anxiety level, which is remarkable knowing how crucial is the role of 5-HT in these behaviors. Therefore, this study unraveled VGLUT3 as a multifunctional transporter that regulated 5-HT neurons and anxiety-like behaviors.

\section{Materials and Methods}

Vglut $^{+/+}$and Vglut3 $3^{-1-}$ mice (Gras et al., 2008) were housed together in groups of 2-4 per cage in a temperature-controlled room with a 12:12 $\mathrm{h}$ dark/light cycle. Food and water were provided ad libitum. Wild-type age- and sex-matched littermates were used as controls. Unless specified (as for behavioral studies for example) both male and female were used. Sex differences were systematically assessed before pooling genders. Except for the ultrasonic vocalizations experiment, all animals were adults between 3 and 6 months of age. Animal studies were performed in accordance with the European Communities Council Directive (86/809/EEC) regarding the care and use of animals for experimental procedures in compliance with the Ministère de l'Agriculture et de la Forêt, Service Vétérinaire de la Santé et de la Protection Animale (permission \# A 94-02821). All experiments were performed with wild-type and homozygous littermates derived from crossing heterozygous gglut $^{+/-}$mice (129/ Sv $\times$ C57BL/6).

Autoradiography of $5-H T_{1 A^{-}}$and $5-H T_{1 B^{-}}$mediated $\left[{ }^{35} S\right] G T P-\gamma-S$ binding. Mice were decapitated, their brains frozen by immersion in isopentane chilled at $-30^{\circ} \mathrm{C}$ with dry ice, and then stored at $-80^{\circ} \mathrm{C}$. Coronal sections $\left(20 \mu \mathrm{m}\right.$ thick) were then cut at $-20^{\circ} \mathrm{C}$, and thawmounted onto gelatin-coated slides. Autoradiographic measurement of $5-\mathrm{HT}_{1 \mathrm{~A}}$ receptor-stimulated $\left[{ }^{35} \mathrm{~S}\right] \mathrm{GTP}-\gamma$-S binding in the DRN and the $\mathrm{CAl}$ area of the hippocampus was performed according to (Froger et al., 2001). Briefly, brain sections were preincubated then incubated with 0.05 nм $\left[{ }^{35} \mathrm{~S}\right] \mathrm{GTP}-\gamma-\mathrm{S}(1000 \mathrm{Ci} / \mathrm{mmol})$ either in the absence (basal conditions) or the presence (stimulated conditions) of 5-carboxamidotryptamine (5-CT, a nonselective potent $5-\mathrm{HT}_{1 \mathrm{~A}}$ receptor agonist) at four different concentrations $\left(10^{-9}, 10^{-8}, 10^{-7}, 10^{-5} \mathrm{M}\right)$. Nonspecific binding was determined in the presence of $10^{-5} \mathrm{M}$ WAY 100635 to block $5-\mathrm{HT}_{1 \mathrm{~A}}$ receptors (Fletcher et al., 1996). Autoradiographic measurement of $5-\mathrm{HT}_{1 \mathrm{~B}}$ receptor-stimulated $\left[{ }^{35} \mathrm{~S}\right] \mathrm{GTP}-\gamma-\mathrm{S}$ binding was performed on brain slices containing the substantia nigra $(\mathrm{SN})$. Brain sections were preincubated then incubated with $0.05 \mathrm{~nm}\left[{ }^{35} \mathrm{~S}\right] \mathrm{GTP}-\gamma-\mathrm{S}(1000 \mathrm{Ci} /$ $\mathrm{mmol}$ ) either in the absence (basal conditions) or the presence (stimu- lated conditions) of 5-CT $10^{-5} \mathrm{M}$. Nonspecific binding was determined in the presence of GR127 $93510^{-5}$ M. 5-CT-stimulated [ $\left.{ }^{35} \mathrm{~S}\right] \mathrm{GTP}-\gamma$-S binding is expressed by the difference between optical density (O.D.) values on autoradiograms from sections incubated with 5-CT and those under basal conditions.

Semiquantitative analysis of in situ hybridization, immunoautoradiography, and autoradiography results. Immunoautoradiography (supplemental Fig. S1, available at www.jneurosci.org as supplemental material) and autoradiography sections performed with ${ }^{125}$ I-labeled ligands were exposed to x-ray films (Biomax MR, Eastman Kodak), scanned and converted to 16-bit images using a Umax PowerLook 1100 scanner (Umax Systems). ${ }^{35} \mathrm{~S}$ - and ${ }^{3} \mathrm{H}$-labeled sections were exposed to BAS-TR Fuji Imaging screens (Fuji Film Photo Co.). Screens were then scanned with a Fuji Bioimaging Analyzer BAS-5000 (Fuji Film Photo Co.). Digitized images were analyzed with the MCID software (Imaging Research) and O.D. was measured as previously described (Kashani et al., 2007). The background density was determined at the level of the white matter and was automatically subtracted. Results are expressed as means of O.D. values (in arbitrary units) \pm SEM.

Immunohistochemistry. Mice were deeply anesthetized and intracardially perfused with $4 \%$ paraformaldehyde in PBS. Brains were dissected, postfixed by immersion in the same fixative and cryoprotected in PBS containing $10 \%$ sucrose. Brains were then frozen in isopentane at $-30^{\circ} \mathrm{C}$. Coronal sections $(10 \mu \mathrm{m})$ were cut using a cryostat, mounted onto glass slides and stored at $-20^{\circ} \mathrm{C}$ until use. Before staining, sections were microwaved in $10 \mathrm{~mm}$ EDTA solution for $5 \mathrm{~min}$, and briefly rinsed with PBS. Immunofluorescence was performed as previously described (Gras et al., 2008). Sections were incubated with crude VGLUT3 guinea pig polyclonal antiserum (1:5000) (Gras et al., 2008), VMAT2 guinea pig antiserum (1:5000) (Gras et al., 2008), 5-HT rat monoclonal antiserum (1:50, Millipore Bioscience Research Reagents), and 5-HT transporter (SERT) mouse antiserum (1:5000, Millipore Bioscience Research Reagents). Primary antibodies were detected with anti-rabbit, anti-guinea pig or anti-mouse IgG coupled to Alexa Fluor 488, Alexa Fluor 555 or Cy5 (Invitrogen). Images were obtained with a confocal laser scanning microscope (Leica TCS SP5 with LCS Leica software). Semiquantification of VGLUT3 colocalization in 5-HT fibers was performed with the ImageJ Software package.

Extracellular recording from brain slices. Mice were decapitated, and their brains were rapidly removed and immersed in an ice-cold artificial CSF (aCSF) of the following composition (mM): $126 \mathrm{NaCl}, 3.5 \mathrm{KCl}, 1.2$ $\mathrm{NaH}_{2} \mathrm{PO}_{4}, 1.3 \mathrm{MgCl}_{2}, 2.0 \mathrm{CaCl}_{2}, 25 \mathrm{NaHCO}_{3}, 11$ D-glucose, continuously gassed with carbogen $\left(95 \% \mathrm{O}_{2} / 5 \% \mathrm{CO}_{2}\right)$ to maintain $\mathrm{pH}$ value at 7.3. A block of tissue containing the DRN was cut into $400 \mu \mathrm{m}$ thick coronal sections in the same ice-cold aCSF using a vibratome. Brainstem slices were immediately incubated in oxygenated aCSF for $\sim 1 \mathrm{~h}$ at room temperature. A single slice was then placed on a nylon mesh, completely submerged in the recording chamber and continuously superfused with oxygenated aCSF $\left(34^{\circ} \mathrm{C}\right)$ at a constant flow rate of $2-3 \mathrm{ml} / \mathrm{min}$ (Lanfumey et al., 1999). Extracellular recordings of the firing of DRN serotonergic neurons were made using glass microelectrodes filled with 2 $\mathrm{m} \mathrm{NaCl}(12-15 \mathrm{~m} \Omega)$. Cells were identified as 5-HT neurons according to previously described criteria (Lanfumey et al., 1999). Firing was evoked in the otherwise silent neurons by adding the $\alpha 1$-adrenoceptor agonist phenylephrine $(3 \mu \mathrm{M})$ into the superfusing aCSF (Vandermaelen and Aghajanian, 1983).

Electrical signals were fed into a high-input impedance amplifier (VF 180, BioLogic), an oscilloscope and an electronic rate meter triggered by individual action potentials, connected to an A/D converter and a personal computer (Lanfumey et al., 1999). Using dedicated software, the integrated firing rate was recorded, computed, and displayed on a chart recorder as consecutive $10 \mathrm{~s}$ samples. Baseline activity was recorded for at least $10 \mathrm{~min}$ before the infusion (lasting $3 \mathrm{~min}$ each) of increasing concentrations of ipsapirone into the chamber, via a three-way tap system. The effects of ipsapirone were evaluated by comparing the mean discharge frequency during the $2 \mathrm{~min}$ period before its application with that recorded at the peak action of the drug (i.e., 2-3 min after its removal from the superfusing aCSF). Data are expressed as percentage of the baseline firing rate \pm SEM. Nonlinear regression fitting was performed 
using Prism 4.0 (GraphPad) software for the calculation of $\mathrm{EC}_{50}$ values for ipsapirone.

Whole tissue measurements of 5-HT, dopamine, norepinephrine and metabolites. Tissue levels of endogenous 5-HT, dopamine (DA) and their metabolites 5-hydroxyindolacetic acid (5-HIAA), 3,4-dihydroxyphenylacetic acid (DOPAC) and homovanillic acid (HVA) were determined as follows. Dissected brain structures were homogenized in 5-10 volumes $(\mathrm{v} / \mathrm{w})$ of ice-cold $0.1 \mathrm{M} \mathrm{HClO}_{4}$ containing $1.34 \mathrm{~mm}$ disodium EDTA and $0.05 \% \mathrm{Na}_{2} \mathrm{~S}_{2} \mathrm{O}_{5}$. Homogenates were centrifuged at $30,000 \times g$ for $20 \mathrm{~min}$ at $4^{\circ} \mathrm{C}$. After neutralization with $2 \mathrm{M} \mathrm{KH}_{2} \mathrm{PO}_{4} / \mathrm{K}_{2} \mathrm{HPO}_{4}, \mathrm{pH} 7.4$, containing $0.01 \mathrm{mg} / \mathrm{ml}$ ascorbate oxidase (Boehringer Mannheim), supernatants were further centrifuged at $30,000 \times g$ for $20 \mathrm{~min}$. Aliquots $(10 \mu \mathrm{l})$ of clear supernatants were injected into a high performance liquid chromatography (HPLC) column (Ultrasphere IP, Beckman; $25 \times 0.46 \mathrm{~cm}, \mathrm{C} 18$ reversed phase, particle size $5 \mu \mathrm{m}$ ) protected with a Brownlee precolumn $(3 \mathrm{~cm}, 5 \mu \mathrm{m})$. The mobile phase for the elution (at a flow rate of $1 \mathrm{ml} / \mathrm{min}$ ) consisted of (in $\mathrm{mm}$ ): $\mathrm{KH}_{2} \mathrm{PO}_{4}, 70$; triethylamine, 3.1; disodium EDTA, 0.1 ; octane sulfonate, 1.05 ; methanol, $16 \%$, adjusted to $\mathrm{pH} 3.02$ with solid citric acid. The electrochemical detection system (ESA 5011) comprises an analytical cell with dual coulometric monitoring electrodes $(+50$ and $+350 \mathrm{mV})$. The generated signals were integrated by a computing integrator (Millenium 32; Waters).

Microdialysis. Microdialysis experiments were performed as previously described (Guilloux et al., 2006). Animals were anesthetized with a combination of ketamine $(100 \mathrm{mg} / \mathrm{kg}$, i.p.) and xylazine $(5 \mathrm{mg} / \mathrm{kg}$, i.p.). After loss of toe pad reflexes, mice were mounted in a Kopf stereotaxic frame in the flat skull position. Microdialysis probes were implanted into the DRN and the hippocampus. The coordinates for these sites were based on Hof's mice brain atlas (Hof et al., 2000) (DRN: anteroposterior, $-5.2 \mathrm{~mm}$ from bregma, lateral 0 , depth, $-4 \mathrm{~mm}$; hippocampus: anteroposterior, $-3.4 \mathrm{~mm}$ from bregma, lateral, $\pm 3.4 \mathrm{~mm}$, depth, $-4 \mathrm{~mm}$ ). The microdialysis probes were anchored to the skull with superglue and embedded in acrylic cement. After completion of the surgery, mice were housed in individual cages and maintained under standard laboratory conditions. Microdialysis experiments were performed the next day. At the end of the experiment, placement of microdialysis probes was verified by histological examination. When a probe was incorrectly placed, the corresponding results were discarded. Paroxetine $(10 \mathrm{mg} / \mathrm{kg})$, a selective 5-HT reuptake inhibitor, was dissolved in $0.1 \mathrm{ml}$ of saline. (Each animal was referred to its own baseline represented by the data obtained after injection of saline). Mice were attached to a fluid swivel $3 \mathrm{~h}$ before the experimental session. The length of the exchange surface of the dialysis membrane was $2 \mathrm{~mm}$ in the hippocampus and $1 \mathrm{~mm}$ in the raphe. Dialysis probes were perfused with artificial CSF (aCSF) containing (in mM): $140 \mathrm{NaCl}, 3 \mathrm{KCl}, 1.5 \mathrm{CaCl}_{2}, 1 \mathrm{MgCl}_{2}, 1.2 \mathrm{NaH}_{2} \mathrm{PO}_{4}, 0.27 \mathrm{Na}_{2} \mathrm{HPO}_{4}$ and $\mathrm{pH}$ was adjusted to 7.4. The aCSF was infused at 0.5 and $1.5 \mu \mathrm{l} / \mathrm{min}$ for DRN and hippocampus respectively, using a microdialysis pump (Phymep) (Guilloux et al., 2006). Infusion was started $3 \mathrm{~h}$ before experiments to allow sufficient time for wash-out of 5-HT originating from non-neural sources. Samples were collected at 30 or 15 min intervals for DRN and hippocampus respectively, and analyzed by HPLC with amperometrical detection. The amount of 5-HT in samples was calculated by measurement of peak heights relative to known amounts in external standards (Guilloux et al., 2006). The limit of sensitivity for 5-HT was $\sim 0.5$ fmol per sample (signal-to-noise ratio $=2$ ).

Subcellular fractionation and amino acid uptake assay. Rats or mice were killed by decapitation. Brains were removed and striatum, cerebral cortex and hippocampus were dissected on ice and resuspended in icecold sucrose $(0.32 \mathrm{M})$. Synaptic vesicles were purified as previously described for the striatum (Huttner et al., 1983; Gras et al., 2008). Transport reaction was started by adding $10 \mu \mathrm{l}$ of synaptic vesicles ( $25 \mu \mathrm{g}$ of protein) to $90 \mu \mathrm{l}$ of uptake buffer containing $2.2 \mathrm{~mm} \mathrm{ATP,} 1.1 \mathrm{~mm} \mathrm{MgSO}_{4}$, and $0.55 \mu \mathrm{Ci}(50 \mathrm{~nm})\left[{ }^{3} \mathrm{H}\right] 5-\mathrm{HT}$ (both from GE Healthcare), with or without $2 \mu \mathrm{M}$ reserpine, and other additives: L-glutamate (10 mM), GABA (10 mM), L-aspartate (10 mM), L-glutamine (10 mM), Trypan Blue (2 $\mu \mathrm{M})$, Evans Blue $(5 \mu \mathrm{M})$, as stated in Results and figure legends. After incubation at $37^{\circ} \mathrm{C}$ for $10 \mathrm{~min},\left[{ }^{3} \mathrm{H}\right]$-amino acid uptake was stopped by dilution in $3 \mathrm{ml}$ of ice-cold $0.15 \mathrm{M} \mathrm{KCl}$, rapid filtration through mixed cellulose esters filters (MF, $0.45 \mu \mathrm{m}$ pore size, Millipore), and 3 washes with 3 $\mathrm{ml}$ of ice-cold $0.15 \mathrm{M} \mathrm{KCl}$. The radioactivity retained on filters was measured by scintillation counting in Ready Protein Cocktail (Beckman). Each condition was measured in triplicate and independent experiments were performed 3 or more times using different synaptic vesicle preparations.

8-OH-DPAT-induced hypothermia. Core body temperature was measured at ambient temperature of $23 \pm 1^{\circ} \mathrm{C}$ using a thermocouple probe (Betatherm; $1.5 \mathrm{~mm}$ diameter). Male mice were gently restrained, and the probe was inserted $20 \mathrm{~mm}$ into the rectum. Basal value was determined just before subcutaneous injection of the $5-\mathrm{HT}_{1 \mathrm{~A}}$ receptor agonist 8 -OH-DPAT $(0.06,0.1$, or $0.3 \mathrm{mg} / \mathrm{kg})$ or vehicle $(0.9 \% \mathrm{NaCl}, 1 \mathrm{ml} / 100 \mathrm{~g}$ body weight), and body temperature was measured every $10 \mathrm{~min}$ thereafter. The response to 8-OH-DPAT was calculated as the maximum decrease (from baseline) in body temperature during a 60 min postinjection period.

Elevated plus maze. Behavioral tests were performed on male subjects. The elevated plus maze was placed into a 50 lux ambient light. After $1 \mathrm{~h}$ of habituation in the testing room, animals were placed into the central area of the maze and tested for $360 \mathrm{~s}$. The total time spent in each compartment (open vs closed arms) was recorded.

Marble burying test. The floor of clear Plexiglas box $(14 \times 32 \times 13 \mathrm{~cm})$ was covered with a $5 \mathrm{~cm}$ layer of sawdust bedding. Twelve glass marbles $(20 \mathrm{~mm}$ diameter) were evenly spaced in four rows of 3 . Mice were individually placed in the cage for $1 \mathrm{~h}$. The number of marbles more than two-thirds covered with sawdust was recorded at different time points.

Novelty-suppressed feeding test. The day before the test, mice were weighed, and food was removed from the cage whereas water remained available ad libitum. Twelve hours after food removal, mice were transferred to the testing room for a $1 \mathrm{~h}$ habituation period. The testing apparatus consisted of a clear Plexiglas box $(14 \times 32 \times 13 \mathrm{~cm})$ with a removable lid. The floor was covered with sawdust bedding. A small piece of mouse chow was placed in the center of the arena on a white circular filter paper (5 $\mathrm{cm}$ in diameter). Each subject was placed in the corner of the testing area opposite to the experimenter. Number of approach toward the food and the latency to start feeding was recorded. Immediately after the mouse began to eat the chow, the tested animal was placed alone in its home cage with a weighed piece of chow for 5 min. Number of approach toward the food and the latency to start feeding was again recorded. After the test, mice were returned to their home cage with food and water provided ad libitum. The novelty-suppressed feeding (NSF) test after 5-HT depletion was performed as described above, with the following modifications. 4-Chloro-DL-phenylalanine methyl ester hydrochloride (PCPA, Sigma-Aldrich) was administered daily for $3 \mathrm{~d}(300 \mathrm{mg} / \mathrm{kg}$, i.p.). After the last injection, food was removed from the cage. Twenty-four hours after food removal and the NSF test was performed.

Ultrasonic vocalization measurement. The ultrasonic vocalization (USV) recordings were obtained from $8 \mathrm{~d}$ postnatal age mice. The animal was placed in a home-made, sound-attenuated, thermoregulated Plexiglas chamber connected to an ultrasound bat detector D230 (Petterson Elektronic $\mathrm{AB})$. The frequency range of the detector $(10-120 \mathrm{kHz})$ included the frequency range of USVs in newborn mice $(40-90 \mathrm{kHz})$ (Branchi et al., 2001). The microphone was placed inside the animal chamber and connected to the electronic processing device via hermetic pass-through connection. Sounds were digitized at $200 \mathrm{kHz}$ (16 bits, PCI 6143, National Instruments) and stored on disk using a homemade Labview program. Contamination of USV recording by parasite sound signals was carefully avoided. The measurement chamber of the plethysmograph was immersed in a closed thermoregulated water bath, which isolated the USV microphone from external noises and maintained the chamber temperature at $32.8^{\circ} \mathrm{C}$. The pups were free from contact stimuli, which are potent triggers of USVs in newborn rodents (Branchi et al., 2001). The bias flow through the plethysmograph had controlled compositions and did not carry odors, which are potent USV triggers. The harmonic structures and bandwidth of ultrasound recordings (40-90 $\mathrm{kHz}$ ) were typical for USVs, indicating that contamination by parasite sounds caused by friction against the walls of the chamber did not occur. Thus, our ultrasound data faithfully reflect the sounds produced by the 

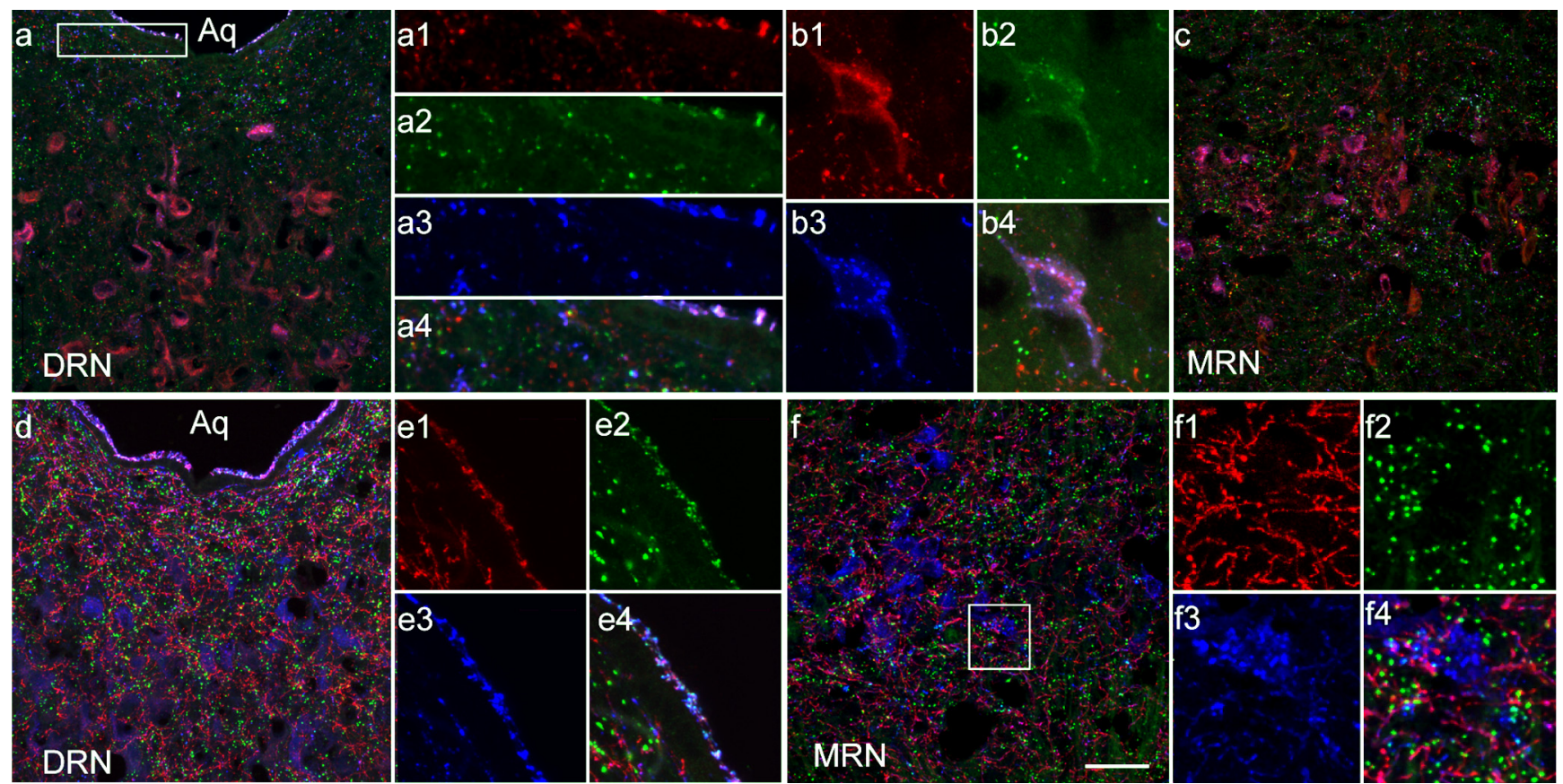

Figure 1. VGLUT3 is poorly present in serotonergic fibers in the raphe. $\boldsymbol{a}-\boldsymbol{c}$, Immunohistochemistry for VGLUT3 (green), 5HT (blue) and VMAT2 (red) in the DRN (a, $\boldsymbol{b})$ and MRN (c). VGLUT3positive terminals almost never colocalise with 5-HT and VMAT2 in the DRN (a) or the MRN (c), whereas the supra-ependymal 5-HT axons contain both VMAT2 and VGLUT3 (a 1-a4). VGLUT3 is also found in some serotonergic somas in large organelles containing both 5-HT and VMAT2 (b1-b4). (d-f) Immunohistochemistry for VGLUT3 (green), 5HT (blue) and SERT (red) in the DRN (d, $\boldsymbol{e}$ ) and $\operatorname{MRN}(\boldsymbol{f})$. VGLUT3-positive terminals never colocalized with SERT in DRN $(\boldsymbol{d}, \boldsymbol{e})$ or MRN $(\boldsymbol{f}$, at higher magnification in $\boldsymbol{f} \mathbf{1}-\boldsymbol{f} \boldsymbol{4})$, except in 5 -HT supra-ependymal axons $(\boldsymbol{e} 1-\boldsymbol{e} 4)$. Scale bars: $\boldsymbol{a}, \boldsymbol{c}, \boldsymbol{d}, \boldsymbol{f}$, $40 \mu \mathrm{m} ; \boldsymbol{a} 1-a 4, \boldsymbol{b 1}-b 4, e 1-e 4,20 \mu \mathrm{m}$, in $\mathbf{f 1 - f 4 ,} 10 \mu \mathrm{m}$.

a

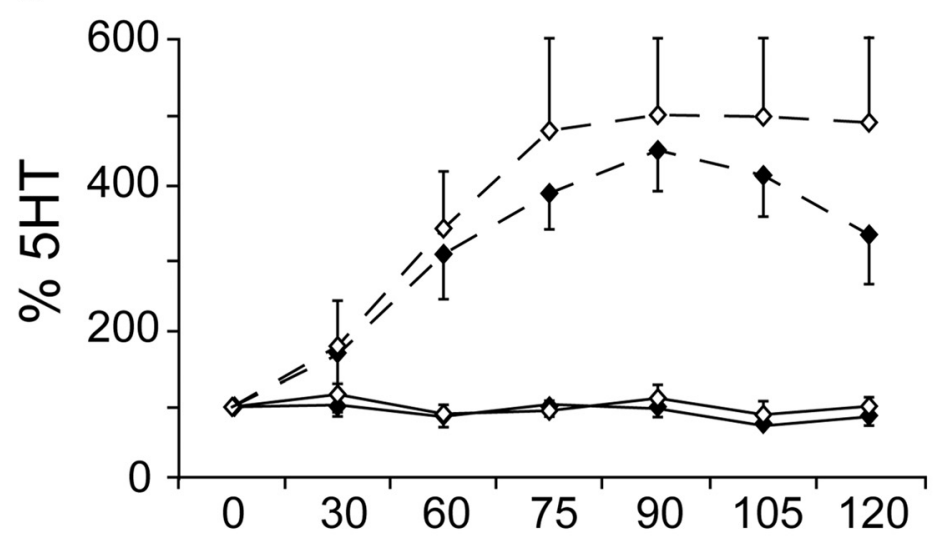

Time after ip injection (minute)

$$
\begin{array}{ll}
-\diamond-\quad+/+10 \mathrm{mg} \text { per kg paroxetine } \\
-\diamond-\quad \text {-/- } 10 \mathrm{mg} \text { per kg paroxetine }
\end{array}
$$

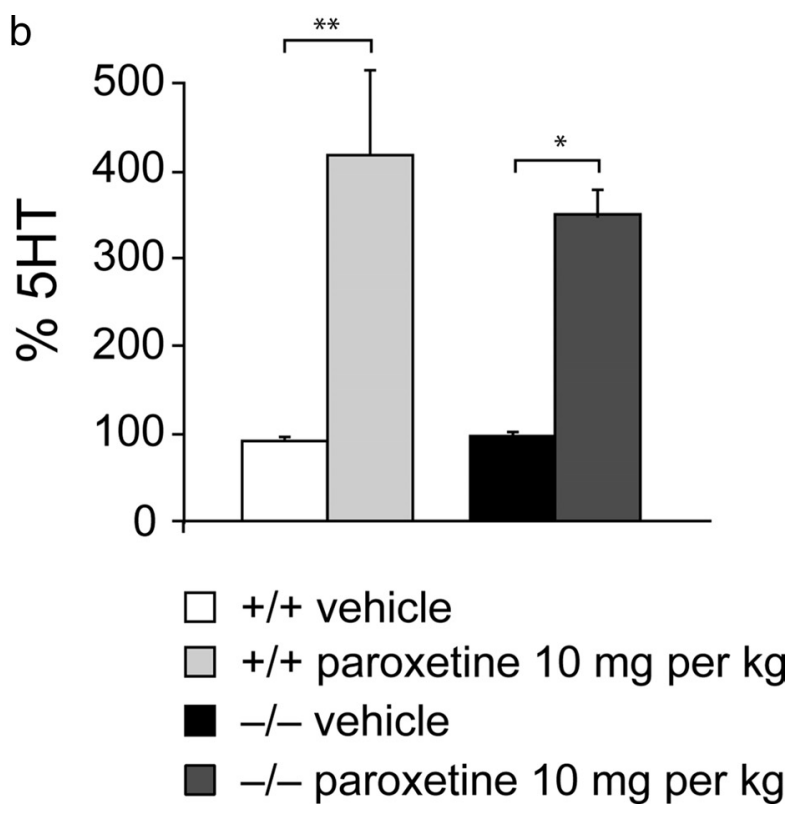

Figure 2. VGLUT3 deletion does not modify 5-HT outflow in the raphe. Extracellular levels of 5-HT were measured in the DRN by in vivo microdialysis coupled to HPLC after injection of saline or paroxetine (i.p., $10 \mathrm{mg} / \mathrm{kg}$ ). $\boldsymbol{a}$, The time course of saline (solid lines) or paroxetine (dashed lines)-induced 5-HT outflow (measured every $15 \mathrm{~min}$ during $90 \mathrm{~min}$ ) did not differ between $\mathrm{Vg} / \mathrm{lut} 3^{+/+}$ and Vglut3 ${ }^{-I-}$ animals (Repeated-measures ANOVA, $F=0.241, p=0.9593$ ). $\boldsymbol{b}$, No difference was found between genotypes in 5 -HT outflow after saline injection. In both genotypes, paroxetine induced a marked augmentation of $5-\mathrm{HT}$ extracellular levels $\left(n=7\right.$, Mann-Whitney, Vglut $^{+/+}, p=0.0017$, Vglut $\left.^{-/-}, p=0.0181\right)$.

pups. Total USV durations were calculated over consecutive 30 s periods for each animal during $20 \mathrm{~min}$. There was no latency between the test and the maternal deprivation.

Statistical analyses. Statistical tests used are detailed in the figure legends. All data are expressed as means \pm SEM. Statistical significance was set at $p \leq 0.05$.

\section{Results}

Inhibition of $5-\mathrm{HT}_{1 \mathrm{~A}}$ autoreceptor in $\mathrm{Vglut}^{-/-}$mice

VGLUT3 transcript is massively expressed in 5-HT mouse raphe neurons (Schäfer et al., 2002). We thus decided to explore in more details the consequences of VGLUT3 deletion in raphe nuclei. 
VGLUT3-positive terminals in the raphe nuclei are not serotonergic

We first qualitatively analyzed the distribution of VGLUT3 in raphe nuclei. The raphe area contains a high density of VGLUT3positive terminals (Gras et al., 2002; Herzog et al., 2004). The extent of VGLUT3 colocalization with various serotonergic markers was analyzed in the DRN and MRN by immunofluorescence and confocal microscopy (Fig. 1). As recently proposed (Shutoh et al., 2008), VGLUT3 appeared to be essentially present in non-5-HT varicose fibers and nerve endings of the DRN (Fig. 1a,d). Indeed, we observed that in the raphe's neuropil only a very small number of VGLUT3 terminals expressed serotonergic markers (5-HT, VMAT2, SERT). In some serotonergic somas, a weak VGLUT3 staining overlapped with large intracellular organelles containing VMAT2 and high concentrations of 5-HT (Fig. 1b1-b4). Such large 5-HT-positive granules have been previously reported in the raphe (Kaushalya et al., 2008; Shutoh et al., 2008), and could sustain the somatic release of 5-HT. In the close vicinity of the raphe, VGLUT3 was massively present in SERT+VMAT2 + 5-HTpositive terminals within supra-ependymal 5-HT axons along the borders of the third ventricle/aqueduct (Fig. 1a1-a4,e1-e4).

Overall, the same situation prevailed in the MRN serotonergic somas and neuropil (Fig. 1c,f). Therefore, VGLUT3 coincided only poorly with 5-HT markers in the DRN and MRN.

\section{5-HT outflow in the DRN of Vglut $3^{-/-}$} mice is not modified

In a recent study, we reported that VGLUT3 regulates acetylcholine vesicular filling and consequently influences its release (Gras et al., 2008). To assess whether or not VGLUT3 could be influential on 5-HT release in the raphe, we then evaluated the impact of VGLUT3 ablation on basal and paroxetine-induced extracellular accumulation of 5-HT in this area by in vivo microdialysis. Basal extracellular 5-HT levels were not different between wild-type and $V g l u t 3^{-1-}$ mice in the DRN (fmol per $10 \mu \mathrm{l}$ : Vglut $^{+/+}: 9.3 \pm 0.7$, Vglut $^{-/-}: 12.3 \pm 2.4$, Fig. $2 a, b)$. Acute administration of paroxetine $(10 \mathrm{mg} / \mathrm{kg}$ i.p $)$ induced a significant increase in 5-HT extracellular levels for at least 120 min in both mouse lines (Fig. $2 a, b$ ). The amount of paroxetinestimulated 5-HT extracellular accumulation was similar in the raphe of wild-type and Vglut $3^{-1-}$ mice. Thus, VGLUT3 appeared to have only limited action on 5-HT outflow in raphe nuclei. This result is well in line with the very low proportion of VGLUT3 + 5-HT-positive terminals in this area as well as with the absence of upregulation of TPOH2 transcript in $\mathrm{Vglut}^{-1-}$ mice (supplemental Fig. S1, available at www.jneurosci.org as supplemental material).

5-HT $T_{1 A} R$ are desensitized in the DRN of Vglut $3^{-1-}$ mice Microdialysis experiments suggested that both evoked outflow and basal release of 5-HT are not modified in the raphe of

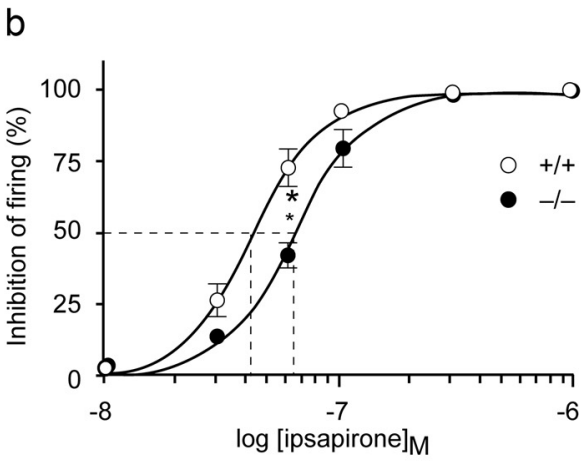

d

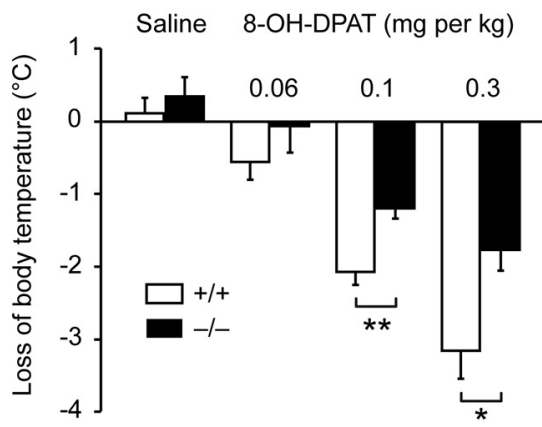

Figure 3. Raphe $5 \mathrm{HT}_{1 \mathrm{~A}}$ autoreceptors are desensitized in Vglut $3^{-1-}$ mice. $\boldsymbol{a}$, Characteristic pacemaker activity of 5-HT neurons was similar between wild-type $(+/+)$ and mutant $(-/-)$ animals $\left(\right.$ Vglut3 $3^{-/}, 1.98 \pm 0.19$ spikes $/ \mathrm{s}, n=14 ;$ Vglut $^{+/+}$ $1.99 \pm 0.13$ spikes $/ s, n=12$ ). Integrated firing rate histograms show that the inhibitory effect of ipsapirone on the electrical of DRN 5-HT neurons is less important in Vglut $3^{-1-}$ mice when compared with wild-type animals. $\boldsymbol{b}$, Concentrationdetermination of ipsapirone $\mathrm{EC}_{50}$ values (abscissa) in both groups (Vglut3 ${ }^{+/+}, \mathrm{EC}_{50}=4.19+0.5210^{-8} \mathrm{M}_{1} n=10 ; \mathrm{Vglut3} 3^{-/-}$ inhibition in Vglut $3^{-1-}$ mice was significantly different from that in Vglut $3^{+/+}$mice $(n=10$, two-way ANOVA, $F=8.59, p=$ 0.0038). c, Autoradiograms of brain sections at the level of the DRN, labeled by [ $\left.{ }^{35} \mathrm{~S}\right] \mathrm{GTP}-\gamma-\mathrm{S}(50 \mathrm{pm})$ in the absence (basal) or the presence (stimulated) of $10^{-5}$ M 5-CT. The concentration-response curves show a desensitization of $5 \mathrm{HT}_{1 \mathrm{~A}}$ autoreceptors in cantly lower in mutant animals (two-way ANOVA, $F=10.23, p=0.004$; Bonferroni, $10^{-7} \mathrm{M} p<0.005,10^{-6} \mathrm{M} p<0.01$ ). 0D, optical density. $\boldsymbol{d}$, The $5 \mathrm{HT}_{1 \mathrm{~A}}$ autoreceptor antagonist 8-0H-DPAT induced a loss of body temperature in both genotypes. At the lowest dose $(0.06 \mathrm{mg} / \mathrm{kg}$, s.c.) the loss of temperature was not significant in wild-type or mutant mice $(n=7$ and $n=8$, respectively). At the $0.1 \mathrm{mg} / \mathrm{kg}$ dose, the temperature loss in Vglut $3^{-/-}$mice $\left(n=7,-1.2 \pm 0.1^{\circ} \mathrm{C}\right.$ ) was significantly less mportant than in Vglut $3^{+/+}$mice $\left(n=7,-2.1 \pm 0.2^{\circ} \mathrm{C}\right.$, Mann-Whitney, $\left.p=0.0045\right)$. This hyposensitivity of Vglut $3^{-1-}$ mice to 8-OH-DPAT-induced hypothermia was confirmed at the dose of $0.3 \mathrm{mg} / \mathrm{kg}\left(\right.$ Vglut $^{-1-}, n=7,-1.8 \pm 0.3^{\circ} \mathrm{C}$, Vglut $^{+/+}, n=$ $8,-3.2 \pm 0.4^{\circ} \mathrm{C}$, Mann-Whitney, $\left.p=0.0278\right)$.

Vglut $^{-1-}$ mice (Fig. 2). However, it could not be ruled out that subtle changes, beyond the detection limit of in vivo microdialysis coupled to HPLC detection could occur. Among the 14 subtypes of 5 -HT receptors, the $5 \mathrm{HT}_{2 \mathrm{~A}}$ and $5-\mathrm{HT}_{1 \mathrm{~A}}$ subtypes have been consistently found to be involved in mood regulation (Caliendo et al., 2005; Weisstaub et al., 2006). As shown in supplemental Figure $S 1$ (available at www.jneurosci.org as supplemental material), $5-\mathrm{HT}_{2 \mathrm{~A}}$ binding sites in limbic areas and in the raphe are not altered following VGLUT3 deletion. 5- $\mathrm{HT}_{1 \mathrm{~A}}$ autoreceptors are present on the soma and dendrites of 5-HT neurons, wherefrom they exert a major inhibitory control on the ascending serotonergic system. These receptors are also expressed by target neurons of 5-HT projections. Interestingly, 5- $\mathrm{HT}_{1 \mathrm{~A}}$ receptors have nanomolar affinity for 5-HT and thus are highly sensitive to subtle variations of extracellular 5-HT concentrations. We thus explored the pacemaker activity of 5-HT neurons and their modulation by $5-\mathrm{HT}_{1 \mathrm{~A}}$ autoreceptors in the DRN of wild-type and mutant mice.

DRN serotonergic neurons recorded in brainstem slices from Vglut $^{-1-}$ mice displayed the characteristic slow and regular pat- 
tern of discharge previously described in rodents (Fig. 3a) (Vandermaelen and Aghajanian, 1983). No change in either frequency or discharge pattern of DRN serotonergic neurons were observed in Vglut $3^{-1-}$ versus $\mathrm{Vglut}^{+/+}$mice. As expected of the stimulation of somatodendritic 5- $\mathrm{HT}_{1 \mathrm{~A}}$ autoreceptors (Mannoury la Cour et al., 2001), superfusing brainstem slices with the 5- $\mathrm{HT}_{1 \mathrm{~A}}$ receptor agonist ipsapirone resulted in a concentration-dependent inhibition of DRN 5-HT neuronal firing (Fig. 3a,b). In both Vglut $3^{-1-}$ and wild-type mice, this effect reached its maximum 2-3 min after ipsapirone application (10-1000 nM) and was progressively washed-out. However, the potency of ipsapirone to inhibit 5-HT neuron firing was significantly lower in mutant than in wildtype mice, as shown by a shift to the right of the concentrationresponse curve (Fig. $3 b$ ). This could be due to a partial desensitization of 5- $\mathrm{HT}_{1 \mathrm{~A}}$ autoreceptors.

The functional coupling of 5- $\mathrm{HT}_{1 \mathrm{~A}}$ receptor to G-proteins was then evaluated in the DRN (Froger et al., 2001). 5-Carboxamidotryptamine (5-CT) induced a concentration-dependent increase in $\left[{ }^{35} \mathrm{~S}\right] \mathrm{GTP}-\gamma$-S labeling (Fig. $3 c$ ), which could be prevented by the selective $5-\mathrm{HT}_{1 \mathrm{~A}}$ receptor antagonist WAY $100635(10 \mu \mathrm{M})$ in both mutant and wild-type mice (data not shown). 5-CTinduced increase in $\left[{ }^{35} \mathrm{~S}\right] \mathrm{GTP}-\gamma$-S binding was significantly lower in Vglut $^{-1-}$ than in Vglut $3^{+/+}$mice (Fig. 3c), strengthening the notion of a $5-\mathrm{HT}_{1 \mathrm{~A}} \mathrm{R}$ desensitization.

Injection of the $5-\mathrm{HT}_{1 \mathrm{~A}} \mathrm{R}$ agonist $8-\mathrm{OH}-\mathrm{DPAT}$ in mice induces a decrease of body temperature that directly depends on the activation of 5- $\mathrm{HT}_{1 \mathrm{~A}}$ raphe autoreceptors (Goodwin et al., 1985; Bill et al., 1991). The sensitivity of $5-\mathrm{HT}_{1 \mathrm{~A}} \mathrm{R}$ in $\mathrm{Vglut}^{+/+}$and Vglut $^{-1-}$ mice was evaluated with 3 doses of 8-OH-DPAT. At the lowest $0.06 \mathrm{mg} / \mathrm{kg}$ dose, no significant decrease in temperature was observed in both genotypes. At 0.1 and $0.3 \mathrm{mg} / \mathrm{kg}$, 8-OH-DPAT induced an important temperature decrease in wild-type animals. Interestingly, $V g l u t 3^{-1-}$ mice showed a weaker decrease of body temperature at both doses when compared with their wild-type littermates. At $0.1 \mathrm{mg} / \mathrm{kg}, \mathrm{Vglut}^{+/+}$ mice showed a decrease of $2.1 \pm 0.2^{\circ} \mathrm{C}$ versus $1.2 \pm 0.1^{\circ} \mathrm{C}$ for Vglut $^{-1-}$ mice (Fig. $3 d$ ). At the $0.3 \mathrm{mg} / \mathrm{kg}$ dose, Vglut $3^{+/+}$mice showed a $3.2 \pm 0.4^{\circ} \mathrm{C}$ decrease of body temperature, versus $1.8 \pm$ $0.3^{\circ} \mathrm{C}$ for the mutant mice (Fig. $3 d$ ).

This set of electrophysiological, biochemical and pharmacological data indicated a functional desensitization of 5- $\mathrm{HT}_{1 \mathrm{~A}}$ autoreceptors in the raphe nuclei of $\mathrm{Vglut}^{-1-}$ mice. All together, these data showed that VGLUT3 has somehow a facilitating effect on the basal activity of 5-HT neurons in wild-type mice.

\section{VGLUT3 synergizes serotonergic tone in a subpopulation of 5-HT terminals}

We next investigated VGLUT3 distribution and function in 5-HT terminals of the prelimbic cortex and the hippocampus.

\section{VGLUT3 colocalizes with VMAT2 and 5-HT, but rarely with SERT}

Previous in situ hybridization results from the literature showed VGLUT3 mRNA expression in a majority of 5-HT somas (Gras et al., 2002; Schäfer et al., 2002). These observations suggested that corresponding terminals could display a mixed glutamatergic/serotonergic phenotype. In forebrain areas receiving 5-HT projections, VGLUT3 protein was essentially observed in varicose fibers and nerve endings (Fig. 4). To further assess the sorting of VGLUT3 in 5-HT terminals, we performed triple immunofluorescence coupled to confocal microscopy between VGLUT3, VMAT2 and 5-HT.

Numerous VMAT2 + 5-HT+VGLUT3 colocalizations were indeed observed within large and fine varicosities of cortical lay- ers I-III (Fig. 4a) and layers V-VI (Fig. 4b). In layer I-III of the prelimbic cortex shown on Figure $4 a, 1423$ varicosities are 5-HTpositive, among which 779 are colabeled by VGLUT3 ( $\approx 55 \%$ ). Of the 827 serotonergic varicosities of layer V-VI (Fig. 4b), 505 also contained VGLUT3 immunoreactivity (i.e., $\approx 61 \%$ of VGLUT3 + 5-HT terminals). Thus, the codistribution of VGLUT3 VMAT2 and 5-HT averaged 50\% in these areas of the prelimbic cortex (Fig. 4a,b). Interestingly, some VMAT2+ VGLUT3 terminals displayed no 5-HT (white arrows, Fig. 4a4,b4) suggesting the existence of various dynamic 5-HT pools or alternatively of adrenergic or histaminergic VGLUT3-positive fibers. In the hippocampus, on Figure $4 c-g$, the amount of VGLUT3-positive 5-HT terminals varied between $33 \%$ in CA1 (Fig. $4 c$ ), 52\% in CA3 (Fig. $4 d$ ), 49\% in the DG (Fig. 4e) and 79\% in the hippocampal fissure (Fig. $4 g$ ). These observations suggested that VGLUT3 distribution in 5-HT terminals from the hippocampus was highly regionalized. In Figure $4 h$, two neurons from the lateral septum are covered by dense VGLUT3-positive pericellular baskets (Riedel et al., 2008; Shutoh et al., 2008). Only one of these neurons is surrounded by VMAT2 + 5-HT+VGLUT3 fibers.

Hence, a substantial amount of VMAT2 +5 -HT terminals in limbic areas (such as the limbic cortex, the hippocampus or the lateral septum) contained VGLUT3. These observations suggested that VGLUT3 could modulate serotonergic transmission in these fibers (Gras et al., 2008).

Since the reuptake transporter SERT is centrally involved in the dynamic regulation of serotonergic transmission, we compared the expression of VGLUT3, 5-HT and SERT (Fig. 4i-k). Unexpectedly, VGLUT3 was only rarely associated with SERTpositive terminals in the lateral septum (Fig. 4i), prelimbic cortex (Fig. 4j) and hippocampus (Fig. 4k). We conclude that VGLUT3 is expressed in a subpopulation of 5-HT terminals containing 5-HT and VMAT2, but only very low levels or no SERT. The heterogeneity of serotonergic fibers has been previously described (Brown and Molliver, 2000). The rarity of SERT on VMAT2 + 5-HT+VGLUT3 nerve endings suggests the existence of terminals displaying enhanced extracellular 5-HT levels after release due to low reuptake.

\section{Hippocampal 5-HT efflux is reduced in Vglut $3^{-/-}$mice}

In a previous study, we established that VGLUT3 increases acetylcholine vesicular filling and release (but not tissue content) in striatal cholinergic terminals (Gras et al., 2008). The anatomical observations of Figure 4 led us to investigate whether cellular or extracellular 5-HT concentrations were changed in the hippocampus of $\mathrm{Vglut}^{-1-}$ mice. Using HPLC, we first measured total levels of 5-HT, DA, NE and the metabolites 5-HIAA, DOPAC, HVA in tissue extracts prepared from various brain areas. Concentrations of these compounds in the cortex, hypothalamus, brainstem or striatum were not detectably altered by the absence of VGLUT3 (Fig. $5 a-g$ ). These results are well in line with the absence of compensatory increase of TPOH2 levels.

However, a small but significant increase in the 5-HIAA/5-HT ratios $(+25 \%$, Fig. $5 c)$ was observed in the hippocampus of Vglut $^{-1-}$ animals suggesting a modified 5-HT turnover. Considering that tissue levels of 5-HT originates mainly from the intracellular stores of 5-HT, the observed change in 5-HIAA/ 5-HT ratios most likely reflects a decrease of the vesicular concentration of 5-HT rather than an increase of 5-HT released and metabolized into 5-HIAA. The 5-HIAA/5-HT ratio is more sensitive than absolute values to detect small decreases in the amount of 5-HT. This result was well in line with the 


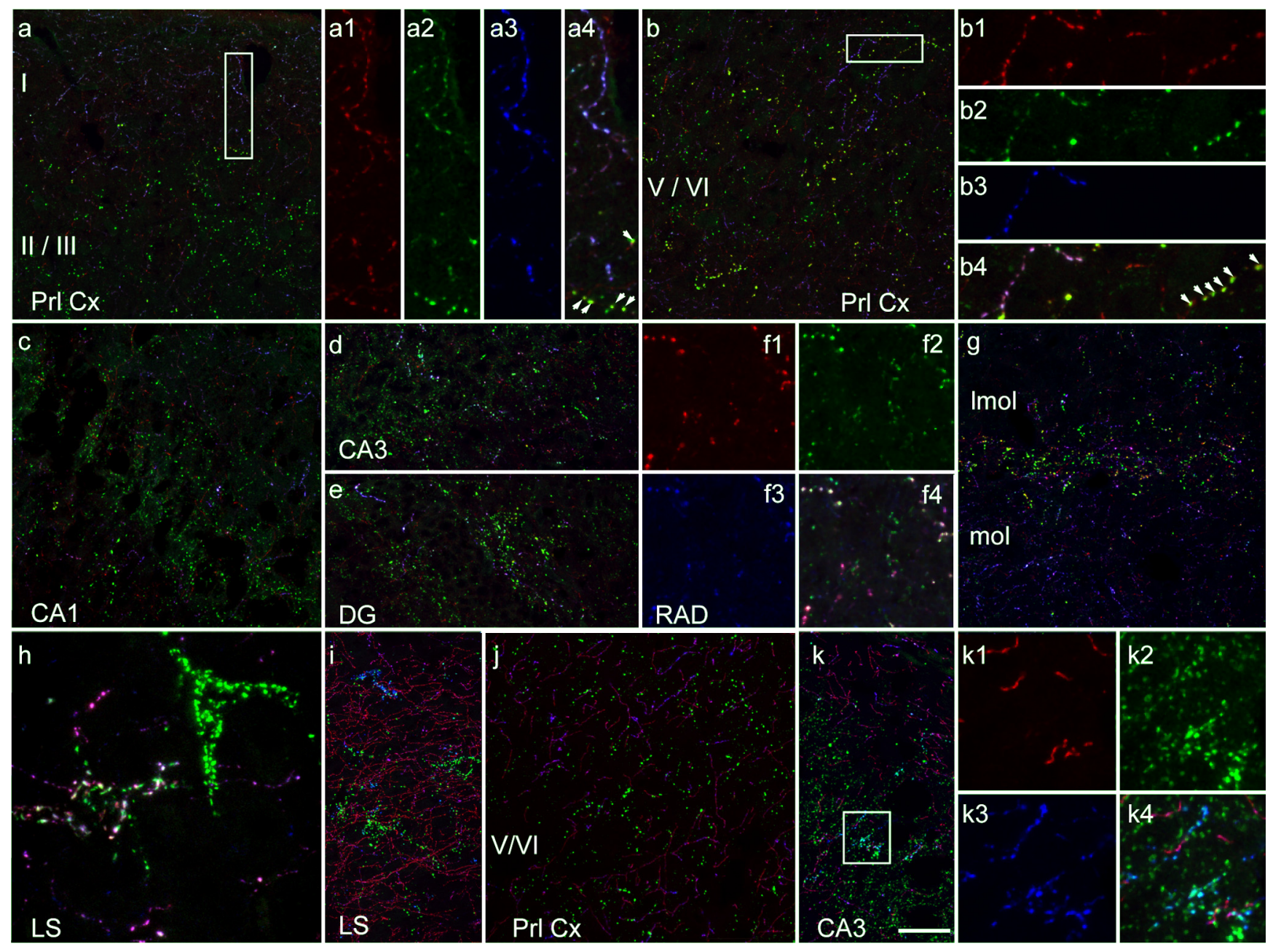

Figure 4. Colocalization of VGLUT3 and VMAT2 in subsets of 5-HT fibers and terminals within limbic areas. VGLUT3-positive terminals (green) are colocalized with VMAT2 (red) and 5 -HT (blue) in the prefrontal cortex ( $\mathrm{Prl}(\boldsymbol{C x})$ in layer I/III and V/VI $(\boldsymbol{a}, \boldsymbol{b})$, in the CA1 and CA3 fields of pyramidal cells $(\boldsymbol{c}, \boldsymbol{d})$ of the hippocampus, in the dentate gyrus (DG) of the hippocampus (e) , in stratum radiatum $(\boldsymbol{f})$, in the hippocampal fissure $(\boldsymbol{g})$, and in the lateral septum (LS) (h). In contrast, VGLUT3-positive (green) 5-HT (blue) terminals rarely coexpressed SERT (red) in the LS (i), Prl Cx (j), and CA3 field $(\boldsymbol{k})$. Regions boxed in $\boldsymbol{a}, \boldsymbol{b}, \boldsymbol{f}$, and $\boldsymbol{k}$ are enlarged and the different channels (red, green, blue and merge) are shown. In some terminals, VGLUT3 is colocalized with VMAT2 but not with 5-HT

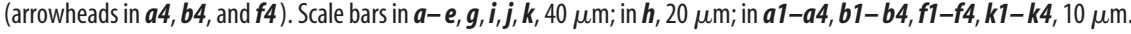

small increase in acetylcholine turn-over detected in the striatum of Vglut $^{-1-}$ mice (Gras et al., 2008).

The amount of 5-HT releasable by serotonergic terminals in the hippocampus was then measured by in vivo microdialysis followed by HPLC. Hippocampal basal extracellular 5-HT levels were not different between wild-type and mutant mice (Fig. $5 h, i)$. Acute administration of the 5-HT reuptake blocker paroxetine (10 mg/kg i.p) (Guilloux et al., 2006) induced a significant and sustained increase in 5-HT levels that lasted at least $2 \mathrm{~h}$ in both mouse lines (Fig. 5h). Interestingly, this increase was significantly smaller in $V g l u t 3^{-1-}$ mice than in wild-type littermates, suggesting a serotonergic deficit in the hippocampus of VGLUT3 deficient mice (Fig. 5i). As previously described (Riad et al., 2001), modification of 5-HT extracellular levels did not influence the functional state of $5-\mathrm{HT}_{1 \mathrm{~A}}$ heteroreceptors in the hippocampus (measured by GTP- $\gamma$-S binding, data not shown).

These changes in 5-HT turnover and outflow in the hippocampus, together with the colocalization of VGLUT3 and VMAT2, are thus reminiscent of observations previously made in the cholinergic system of these mice (Gras et al., 2008).
VGLUT3 increases 5-HT vesicular accumulation

VMAT2 and VAChT belong to the same family of antiporters and share similar bioenergetic properties (Gasnier, 2000). Since VGLUT3 positively modulates acetylcholine vesicular filling (Gras et al., 2008), we investigated whether glutamate was also able to stimulate 5 -HT vesicular accumulation. $\left[{ }^{3} \mathrm{H}\right] 5-\mathrm{HT}$ vesicular uptake was measured in the presence or absence of reserpine (a specific VMAT2 inhibitor). After $10 \mathrm{~min}$ at $37^{\circ} \mathrm{C}, 9.7$ and 14.0 pmol of 5-HT per mg of protein were accumulated in, respectively, hippocampal and cortical vesicles (Fig. 6a). In the presence of glutamate $(10 \mathrm{~mm})$, reserpine-sensitive $\left[{ }^{3} \mathrm{H}\right] 5$-HT uptake by rat hippocampal and cortical vesicles was increased by $+29 \%$ and $+34 \%$, respectively. Thus, rat hippocampal and cortical vesicles accumulated more $\left[{ }^{3} \mathrm{H}\right] 5$-HT in the presence of glutamate. In the rat striatum, where most of VMAT2 is confined to VGLUT3negative dopaminergic terminals, glutamate had no effect on reserpine-sensitive $\left[{ }^{3} \mathrm{H}\right] 5$-HT uptake (Fig. 6a). Therefore, glutamate was able to stimulate 5-HT accumulation only in areas where VGLUT3 and VMAT2 are colocalized in the same terminals. In addition, neither GABA, nor aspartate or glutamine (that are not transported by VGLUT3 (Gras et al., 2002) were able to stimulate 
a

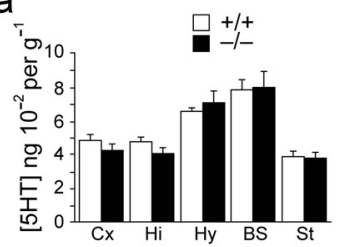

d

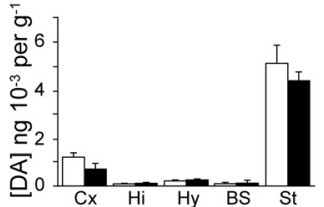

g

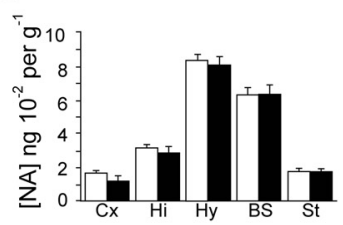

$\mathrm{b}^{-}$

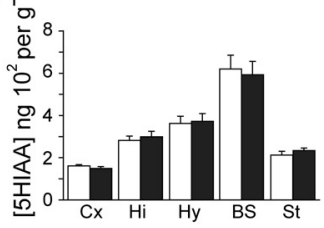

e

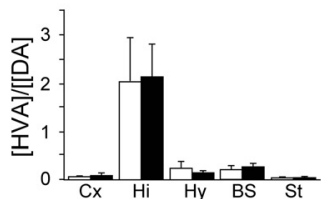

$\mathrm{h}$

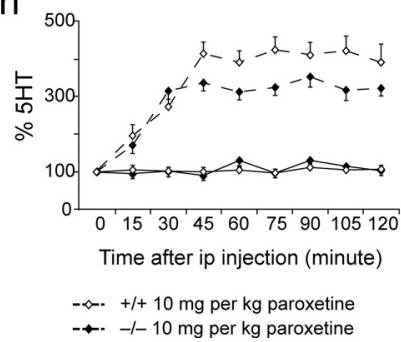

C

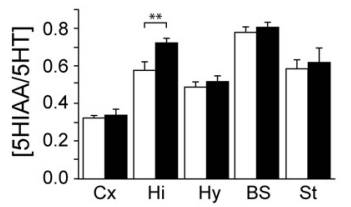

$f$

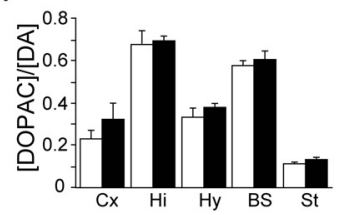

i

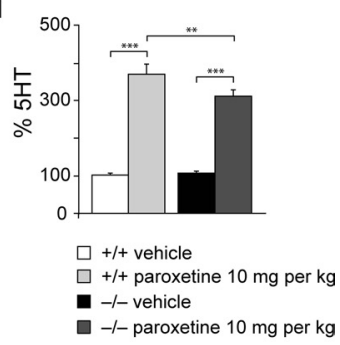

Figure 5. VGLUT3 deletion reduces hippocampal extracellular levels of 5-HT. $\boldsymbol{a}-\boldsymbol{g}$, Levels of 5-HT, DA, NA and metabolites were measured using HPLC coupled to electrochemical detection. Levels of all neurotransmitters and metabolites were unchanged between wild-type (white bars) and mutant (black bars) animals. However, the 5-HIAA/5-HT ratio was augmented in Vglut $3^{-1-}$ mice hippocampi ( $+25 \%$, Mann-Whitney, $p=0.0056)$, reflecting a slightly increased 5HT turnover in this structure. $\boldsymbol{h}-\boldsymbol{i}$, Microdialysis measurements of extracellular 5-HT levels in the ventral hippocampus of $\mathrm{Vglut} 3^{-1-}$ and $\mathrm{Vglut} 3^{+/+}$mice. $\boldsymbol{h}, 5-\mathrm{HT}$ outflow reached a lower plateau in Vglut $3^{-/-}$mice when compared with $V g$ lut $3^{+/+}$mice (Repeated-measures ANOVA, $F=$ $5.905, p<0.0001) . i$, As in the raphe, basal 5 -HT outflow in the hippocampus of wild-type and mutant animals was not different (fmol per $20 \mu \mathrm{l}$ : Vglut $3^{+/+}, 3.54 \pm 1.72$, Vglut3 ${ }^{-1-}, 3.64 \pm 1.12$; repeated-measures ANOVA, $F=0.052, p=0.82$ ). Following paroxetine injection ( $10 \mathrm{mg} / \mathrm{kg}$, i.p.), 5 -HT outflow was significantly increased in both genotypes (Mann-Whitney, $\mathrm{Vglut} 3^{+/+}$, $p<0.0001, n=9$; Vglut $^{-1-}, p<0.0001, n=10$ ). Moreover, paroxetine-induced 5 -HT outflow was significantly lower in mutant mice (Mann-Whitney test, $p=0.0011$ ).

$\left[{ }^{3} \mathrm{H}\right] 5-\mathrm{HT}$ vesicular uptake in the rat cortex (Fig. $6 b$ ). Moreover, the stimulatory effect of glutamate on $\left[{ }^{3} \mathrm{H}\right] 5-\mathrm{HT}$ rat vesicular loading was abolished by inhibitors of VGLUT3 activity, such as Trypan Blue and Evans Blue (Fig. 6b). Finally, to clearly establish that VGLUT3 was responsible for the increased accumulation of 5-HT in cortical vesicles, LP2 fraction from wild-type and Vglut $3^{-1-}$ mice were assayed. As shown in Figure $6 c$, the effect of glutamate on VMAT2 activity was selectively abolished in VGLUT3-deficient vesicles.

To conclude, VGLUT3 is colocalized with VMAT2 in subpopulations of cortical and hippocampal 5-HT terminals. This coexpression of the two vesicular transporters resulted in an increased vesicular accumulation and hence efflux of 5-HT in these brain regions. Thus, the VGLUT3-dependent mechanism revealed in striatal cholinergic synapses also occurred in VGLUT3/ VMAT2-positive 5-HT terminals.

\section{$V_{\text {glut }}{ }^{-/-}$mice display an anxiety-like phenotype}

Inhibition of serotonergic tone has often been associated with mood and anxiety disorders. The above-described results strongly suggested that VGLUT3 was able to positively regulate 5 -HT transmission in limbic areas. Consequently, we speculated that $V g l u t 3^{-1-}$ mice could have disregulated emotional behaviors paralleling their biochemical modifications. We thus decided to characterize these behaviors in adult (3- to 6-month-old) male mice or newborn pups (for ultrasonic vocalizations).

Since 5-HT transmission is implicated in aggressive behavior in both human and rodents (Olivier, 2004), we first tested
Vglut $3^{-1-}$ mice in the resident-intruder test to assess their territorial and social behaviors. When exposed to an unfamiliar intruder in their home cage, $\mathrm{Vglut}^{+/+}$ and Vglut $^{-1-}$ resident mice displayed similar social activity with few rattlings and attacks (data not shown). Thus, $V_{\text {glut }} 3^{-1-}$ mice did not avoid social interactions and did not show any particularly aggressive behavior.

Mice were then tested in the tail suspension test that is classically used to induce a despair-like behavior by submitting the animal to an inescapable situation. After a saline injection, immobility episodes progressively increased in duration in both genotypes, resulting in a similar total amount of immobility. To assess antidepressant-like activity, mice were injected with various doses of an SSRI antidepressant (paroxetine) or norepinephrine reuptake inhibitor (reboxetine) (Fig. 7a). The immobility time was similarly and dose-dependently reduced in both mice lines. Thus, Vglut $3^{-1-}$ mice exhibited no modifications of their sensitivity to SSRI despite the observed modifications of 5-HT transmission.

5-HT is also known for its major contribution to normal and pathological anxiety states. Therefore, we evaluated the anxiety-like behavior of $\mathrm{Vglut}^{+/+}$and Vglut $^{-1-}$ mice in different conflictbased paradigms. In the elevated plus maze test, mice exploration drive was assessed in the open arms vs the closed arms of the apparatus. Vglut $3^{-1-}$ mice made significantly less entries (data not shown) and spent less time in the open arms compared with their wild-type littermates (Fig. 7b). Vertical exploration of the maze was also reduced in Vglut $3^{-1-}$ mice as shown by the number of rearings. This very low level of exploration suggested a marked neophobia of the mutant mice.

We then used the marble burying test based on the defensive tendency of rodents to bury any novel object- even harmlessplaced in their environment. Repetitive sawdust digging and burying of marbles is thought to model stereotypic aspects of obsessive-compulsive disorders (Olivier, 2004). After $30 \mathrm{~min}$ spent into a novel environment, Vglut $3^{-1-}$ mice buried the 12 glass marbles significantly faster than wild-type littermates (Fig. $7 c$ ). This active concealing of novel objects further supports the notion of a strong neophobic component in $\mathrm{Vglut}^{-1-}$ behavior with a tendency to display stereotypic behaviors when placed in conflict situations.

Mice were then tested in a third conflict paradigm, the noveltysuppressed feeding test, based on the novelty-induced suppression of appetitive behavior. Food-deprived $V g l u t 3^{-/-}$and wild type mice did not differ in regard to their loss of weight or their total amount of food-pellet intake (data not shown). When placed in a potentially anxiogenic environment (Fig. $7 d$, new cage, NC), Vglut $3^{-1-}$ mice exhibited a longer latency to start feeding compared with the $\mathrm{Vglut}^{+/+}$animals despite a higher number of approaches toward the food pellets (data not shown). These significant differences did not appear when mice were offered food-pellets in their home cage 

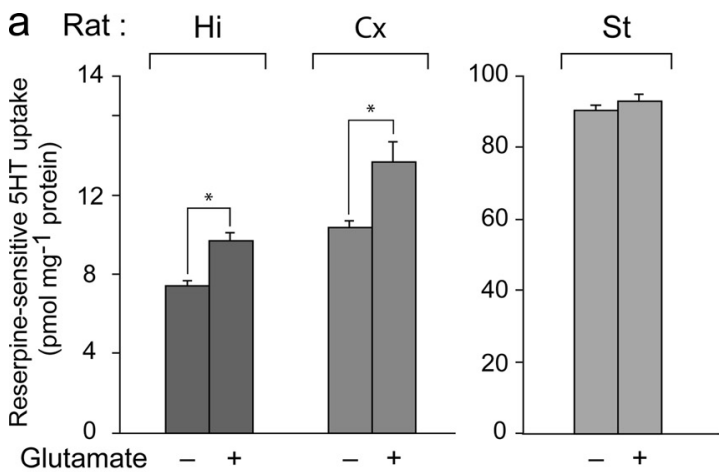

b
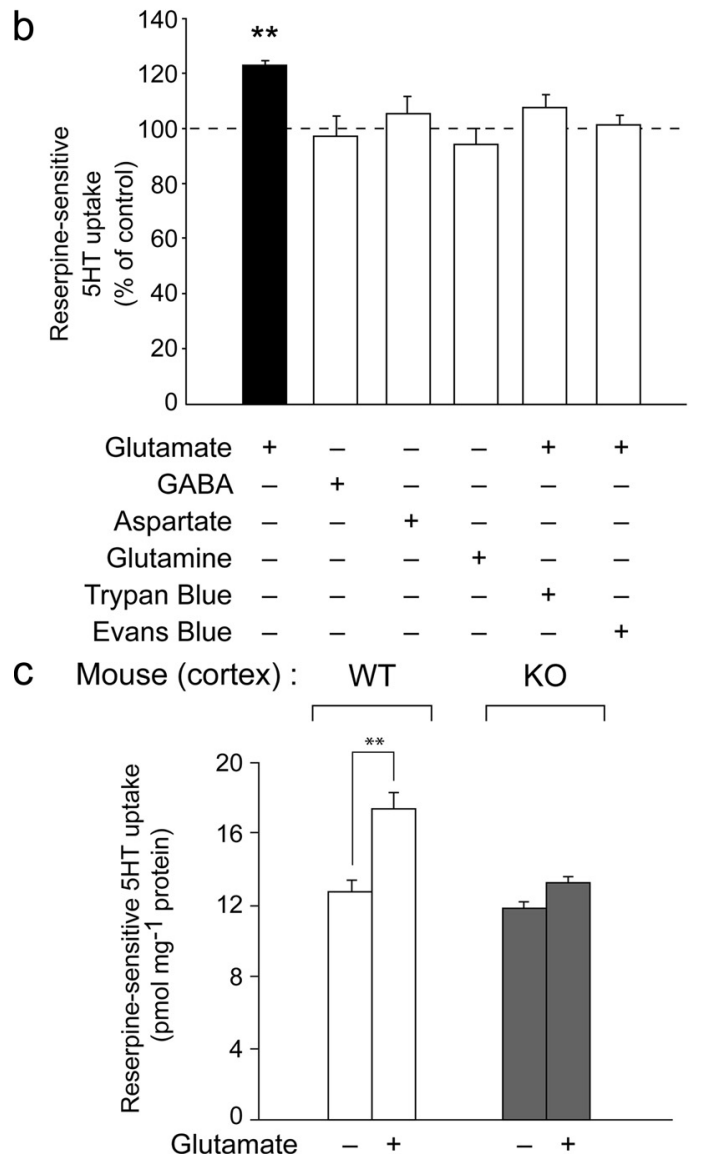

Figure 6. VGLUT3 stimulates vesicular 5 -HT loading. $\boldsymbol{a},\left[{ }^{3} \mathrm{H}\right] 5-\mathrm{HT}$ reserpine-sensitive vesicular accumulation is augmented by L-glutamate $(10 \mathrm{~mm})$ in the rat hippocampus ( $\mathrm{Hi}$, $+29 \%$, Mann-Whitney, $p=0.0369)$ and cortex (Cx, $+34 \%$, Mann-Whitney, $p=$ 0.0369), but not in the striatum (St). $\boldsymbol{b}$, The stimulatory effect of glutamate on $5-\mathrm{HT}$ vesicular uptake had the pharmacological profile of a vesicular glutamate transporter. Cortical reserpine-sensitive 5 -HT vesicular uptake was measured in the presence $(+)$ or absence (-) of different compounds. Reserpine-sensitive $\left[{ }^{3} \mathrm{H}\right] 5-\mathrm{HT}$ was significantly stimulated only by L-glutamate $(+22 \%$, Mann-Whitney, $p=0.0021)$. c, Glutamate effect on $\left[{ }^{3} \mathrm{H}\right] 5-\mathrm{HT}$ uptake into cortical vesicles from $\mathrm{Vglut}^{+/+}$and $\mathrm{Vglut} 3^{-1-}$ mice. L-Glutamate $(10 \mathrm{~mm})$ stimulates uptake into wild-type $(+35 \%$, Mann-Whitney, $p=0.009)$ but not VGLUT3-deficient vesicles.

(Fig. 7d, HC). Novelty-induced anxiety more effectively counteracted the strong feeding drive in Vglut $3^{-1-}$ mice.

The involvement of serotonergic transmission in the anxiouslike behavior of Vglut $^{-1-}$ mice was then evaluated. To challenge 5-HT levels, knock-out and wild-type mice were pretreated with PCPA, a TPOH inhibitor. PCPA pretreatment significantly reduced 5-HT content in the hippocampus of both Vglut $3^{-1-}$ and Vglut $^{+/+}$mice $(-73 \%$ and $-57 \%$ respectively, $p<0.001$, data not shown). Neither striatal dopamine nor hippocampal noradrenaline were altered by this treatment. In the NSF test, PCPA did not significantly change the latency to feed of wild-type animals (Fig. $7 d$, compare NC saline and NC PCPA). In contrast, PCPA-treated Vglut $^{-1-}$ mice displayed a latency to feed similar to that of their wild-type littermates. Thus, the VGLUT3dependent increase in latency to feed when mice are confronted to an anxiogenic environment is affected by 5 -HT levels in the brain. Together, these data strongly suggest that deletion of VGLUT3 leads to an anxiety-related phenotype, at least partly linked to serotonergic transmission in $\mathrm{Vglut}^{-1-}$ mice.

Finally, we investigated whether the enhanced anxiety-related behavior in mutant mice was established early in their development (Fig. 7e). We measured stress-induced ultrasonic vocalizations in pups from both genders on postnatal age P8 (Branchi et al., 2001). At this age, both genotypes are deaf which excludes an influence of Vglut $^{-1-}$ mice deafness on their anxiety levels. Maternal contact deprivation elicited vocalizations in pups of both genotypes but $V_{\text {glut }}{ }^{-1-}$ pups emitted longer trains than Vglut $^{+/+}$animals. No difference was observed between male and female pups. Therefore, an enhanced anxiety-like response of VGLUT3 mutant mice to stressful situations is established at an early developmental stage. Thus, deletion of VGLUT3 impacts on anxiety-related behavior possibly via 5-HT transmission.

\section{Discussion}

Unlike other subtypes of vesicular glutamate transporters, VGLUT3 is expressed preferentially in neurons allegedly using other neurotransmitters than glutamate. The present study was undertaken to clarify both the distribution and the roles of VGLUT3 in 5-HT neurons.

\section{Anatomical heterogeneity of VGLUT3 distribution in 5-HT terminals}

Despite the presence of its mRNA in 5-HT neuronal soma, VGLUT3 is targeted only to limited subsets of 5-HT terminals in projection areas (present study and (Gras et al., 2002; Schäfer et al., 2002; Hioki et al., 2004; Shutoh et al., 2008). We herein report for the first time, that VGLUT3-positive 5-HT terminals lack the 5-HT reuptake site SERT. The complexity of SERT distribution in 5-HT neurons and terminals is well documented (for review, see Molliver, 1987). In the rat cerebral cortex or the nucleus accumbens, 5-HT is found either in a diffuse plexus of fine fibers with fusiform varicosities that express SERT or in SERT-negative varicose axons making large spherical terminals (Kosofsky and Molliver, 1987). As shown in Figure 4, VGLUT3 is associated with large and spherical as well as with fine fusiform serotonergic varicosities. Thus, our own observations provided further evidence of an anatomical complexity of the 5-HT network, and suggested that VGLUT3 sorting in different branches of 5-HT neurons is complex and differentially regulated.

Surprisingly, the numerous 5-HT collateral recurrent fibers sent to raphe nuclei are never endowed with VGLUT3. In addition to, ciliated ependymocytes boarding the third ventricle are surrounded by a dense layer of supra-ependymal serotonergic axons that are both SERT- and VGLUT3-positive. Together, the above described data point to the existence of multiple subpopulations of serotonergic terminals that express either: (1) 5-HT, VMAT2 and SERT, (2) 5-HT, VMAT2, SERT, and VGLUT3, (3) 5-HT, VMAT2 and VGLUT3 (Fig. 8).

\section{VGLUT3 and 5-HT transmission}

The firing rate of serotonergic neurons as well as the synthesis and release of 5-HT are finely regulated by intricate mechanisms involv- 


\section{a Tail suspension test}
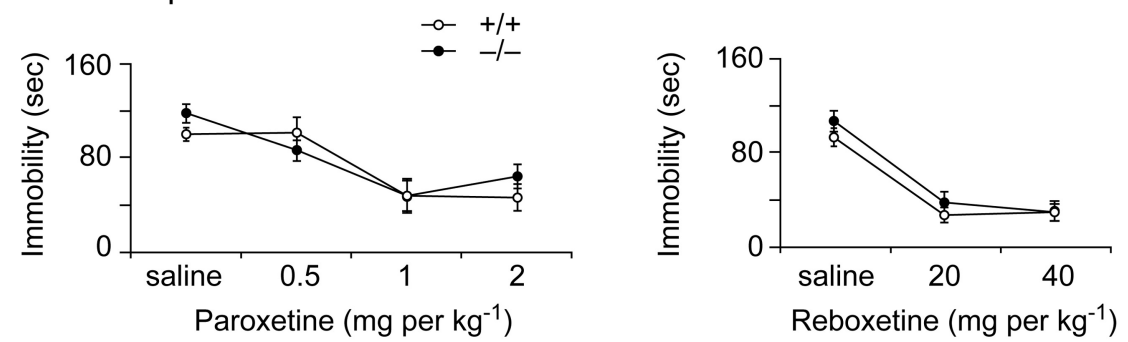

b Elevated plus maze

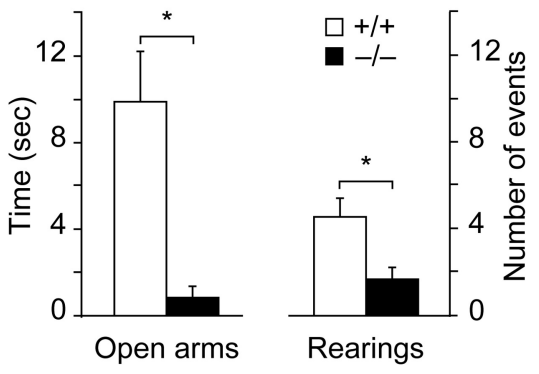

d Novelty suppressed feeding test
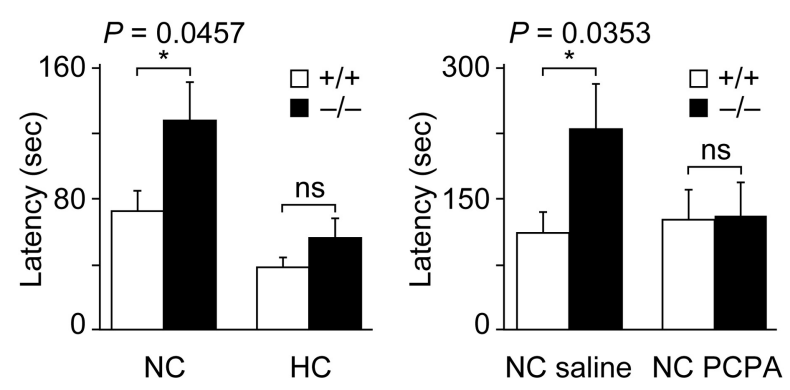

Figure 7. VGLUT3 deletion increases anxiety. $\boldsymbol{a}$, Total immobility time out of $6 \mathrm{~min}$ of recording after saline, paroxetine or intraperitoneal reboxetine injection in the tail suspension test. Wild-type $(+/+)$ and mutant $(-/-)$ mice showed no difference in immobility time after intraperitoneal saline injection. The decrease of immobility time after injection of paroxetine or reboxetine was globally the same between both genotypes. $\boldsymbol{b}$, Anxiety levels appeared higher in mutant mice when assessed in the elevated plus maze. Horizontal and vertical exploration were measured during $6 \mathrm{~min}$. Compared with wild type littermates, Vglut $3^{-1-}$ mice spent less time in the open and bright arms $(n=8$, Mann-Whitney, $p=0.0184)$. Vertical exploration was also reduced in mutant mice as shown by the lower number of rearings (Mann-Whitney, $p=0.0260$ ). $c$, The number of glass marbles buried by Vglut $^{+/+}(n=23)$ and Vglut ${ }^{-1-}(n=25)$ mice was measured during $1 \mathrm{~h}$. Mutant animals buried the marbles faster than did wild-type animals (repeated-measure ANOVA, $F=3.975, p<0.0001$ ), reflecting a higher level of anxiety in the presence of novel objects. $\boldsymbol{d}$, Left: When tested in an unfamiliar environment (new cage, NC), Vglut $3^{-1-}$ mice $(n=20)$ started to feed later ( $t=$ $2.066, p=0.0457)$ compared with Vglut $3^{+/+}$mice $(n=20)$. No difference between genotypes was observed when animals where tested in their home cage (HC). Right: Novelty-suppressed feeding behavior after 5 -HT depletion. The higher latency to feed in an unfamiliar environment observed in Vglut $3^{-1-}$ mice was conserved in groups that received intraperitoneal saline injections

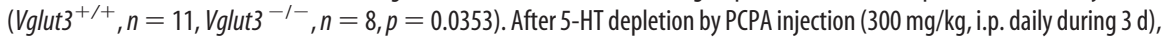
latency to feed in Vglut ${ }^{-/-}$mice $(n=8)$ was reduced to the same level as Vglut ${ }^{+/+}$mice $(n=12)$. $\boldsymbol{e}$, USVs were recorded during $20 \mathrm{~min}$ in 8-d-old Vglut $3^{+/+}$and Vglut $3^{-/-}$pups. Total USV durations were calculated over consecutive $30 \mathrm{~s}$ periods for each animal during the $20 \mathrm{~min}$ of the test and values are expressed as the average duration of USV trains over $30 \mathrm{~s}$. In response to the stress of being separated from mother and littermates, mutant pups emitted more vocalizations than wild type pups (Fisher's PLSD test, $p=0.0128$ ).

ing inter- or intrasynaptic pathways. In this report, we unraveled additional and unsuspected levels of regulation of serotonergic transmission operated by VGLUT3.

\section{1-VGLUT3 modulates 5-HT transmission in the raphe}

The physiological, electrophysiological, biochemical and pharmacological studies that we have undertaken demonstrated the occurrence of a slight, but significant desensitization of $5-\mathrm{HT}_{1 \mathrm{~A}} \mathrm{R}$ inhibitory somatodendritic autoreceptors in the raphe of Vglut $^{-/-}$mice. First, although the typical pacemaker-like firing of 5-HT somas was similar between both genotypes, 5-HT neurons from Vglut3 ${ }^{-1-}$ mice exhibited a decreased sensitivity to the application of the $5-\mathrm{HT}_{1 \mathrm{~A}} \mathrm{R}$ agonist ipsapirone. Second, GTP- $\gamma$-S coupling to 5- $\mathrm{HT}_{1 \mathrm{~A}} \mathrm{R}$ following 5-CT stimulation was reduced in Vglut $3^{-1-}$ mice. Thirdly, stimulation of $5-\mathrm{HT}_{1 \mathrm{~A}}$ autoreceptors by $8-\mathrm{OH}-$ DPAT triggered a smaller body temperature loss in mutated animals. The most plausible interpretation of these findings is that in the raphe nuclei of $\mathrm{Vglut}^{-1-}$ mice, the loss of VGLUT3 induced a small increase of basal extracellular levels of 5-HT, sensed by the high-affinity $5-\mathrm{HT}_{1 \mathrm{~A}}$ receptor. However, the microdialysis method used in the present study was not sensitive enough to detect small variations of 5-HT basal level in the raphe of $\mathrm{Vglut}^{-/-}$and $V g l u t 3^{+/+}$mice.

VGLUT3-positive terminals within the raphe arise either from 5HT neurons or from local VGLUT3-only glutamatergic neurons. Glutamatergic raphe neurons were recently shown to send projections (1) to the hippocampus and the septum (Jackson et al., 2009) and (2) locally to the dorsolateral subdivision of the DRN (Commons and Valentino, 2002; Valentino et al., 2003). In Vglut $^{-1-}$ mice, the lack of VGLUT3 in these glutamatergic fibers somehow triggers the desensitization of $5-\mathrm{HT}_{1 \mathrm{~A}}$ receptors. GABAergic interneurons from the raphe nuclei negatively regulate 5-HT neuronal activity (Gervasoni et al., 2000; Jankowski and Sesack, 2004). The desensitization of $5-\mathrm{HT}_{1 \mathrm{~A}}$ receptor in Vglut $^{-/-}$mice could be linked to VGLUT3positive terminals controlling GABAergic interneurons relaying an inhibitory influence on 5-HT transmission. Hence, the molecular mechanisms leading to the desensitization of $5-\mathrm{HT}_{1 \mathrm{~A}}$ receptor in the raphe of Vglut $^{-1-}$ mice and whether it is an intra- or trans-synaptic process await additional investigations.

\section{2-VGLUT3 stimulates 5-HT \\ transmission in subsets of serotonergic terminals}

VGLUT3 has recently been shown to stimulate vesicular ACh accumulation in striatal cholinergic interneurons (Gras et al., 2008). Since the vesicular transporter of acetylcholine (VAChT) and monoamine (VMAT2) share the same bioenergical properties, we suspected that such a vesicular-filling synergy could occur in VMAT2/VGLUT3-positive terminals. In line with this hypothesis, we found that (1) glutamate stimulates $\left[{ }^{3} \mathrm{H}\right] 5$ HT reserpine-sensitive accumulation in the hippocampus and the cortex and (2) this effect was lost in Vglut $3^{-/-}$mice.

VMAT2 is present in terminals arising from all classes of monoaminergic neurons (i.e., dopaminergic, noradrenergic, his- 
taminergic and serotonergic vesicles). VGLUT3 labels only a subset of serotonergic terminals ( $\approx 50 \%$ in the hippocampus and cortex). Since our assays measured global VMAT2 activity, it was quite startling to detect vesicular-filling synergy in cortical or hippocampal preparations. In striatal vesicles, glutamate dose-dependently stimulated $\left[{ }^{3} \mathrm{H}\right] \mathrm{ACh}$ vesicular accumulation between 0.1 and $10 \mathrm{~mm}$ (Gras et al., 2008). A maximal $+300 \%$ stimulation was observed in the presence of $10 \mathrm{~mm}$ glutamate. The cytoplasmic concentration of glutamate is in the millimolar range while the intravesicular glutamate concentration is estimated $\approx 50 \mathrm{~mm}$ (for review, see Danbolt, 2001). Thus a $10 \mathrm{~mm}$ concentration of glutamate could be physiologically relevant momentarily near the surface of the vesicles. We herein report a $\approx+30 \%$ stimulation of 5-HT reserpine-sensitive accumulation in the presence of $10 \mathrm{~mm}$ glutamate. We thus suspect this stimulatory mechanism to be more important in individual 5-HT terminals. It should be noticed that vesicular-filling synergy occurs in modulatory terminals that are tonically active and display "volume transmission" (Descarries and Mechawar, 2000). Consequently vesicular concentration of 5-HT or ACh appears to be flexibly tuned by glutamate cytoplasmic concentrations in the millimolar range (Gras et al., 2008). Hence, another interesting feature of vesicular-filling synergy is its ability to couple tonically active modulatory transmission to cellular metabolism.

Moreover, the subpopulation of 5-HT hippocampal and cortical fibers expressing VGLUT3 lacked the plasma membrane transporter, SERT. Consequently, in VGLUT3-positive serotonergic terminals, 5-HT release must be augmented by vesicular-filling synergy and prolonged by the lack of plasma 5-HT reuptake. We propose that the differential expression of VGLUT3, VMAT2 and SERT defines functional subclasses of 5-HT terminals (Fig. 8). Serotonergic fibers possessing VMAT2 and VGLUT3 (but not SERT) being the most "powerful" while those containing VMAT2 and SERT (but not VGLUT3) should demonstrate the least efficient 5-HT transmission.

VGLUT3-dependent vesicular-filling synergy was first reported in cholinergic interneurons (Gras et al., 2008) and is now established in subsets of 5-HT terminals. Another vesicular glutamate transporter, VGLUT2, is stably expressed in adrenergic cells groups C1-C3 and transiently in developing dopaminergic neurons (Stornetta et al., 2002; Mendez et al., 2008). It is yet undetermined whether glutamate-dependent stimulatory mechanism occurs in these catecholaminergic terminals. We speculate that vesicular-filling synergy could be a convenient way to locally and timely increase transmission. Vesicular-filling synergy could also be dynamically regulated during developmen-
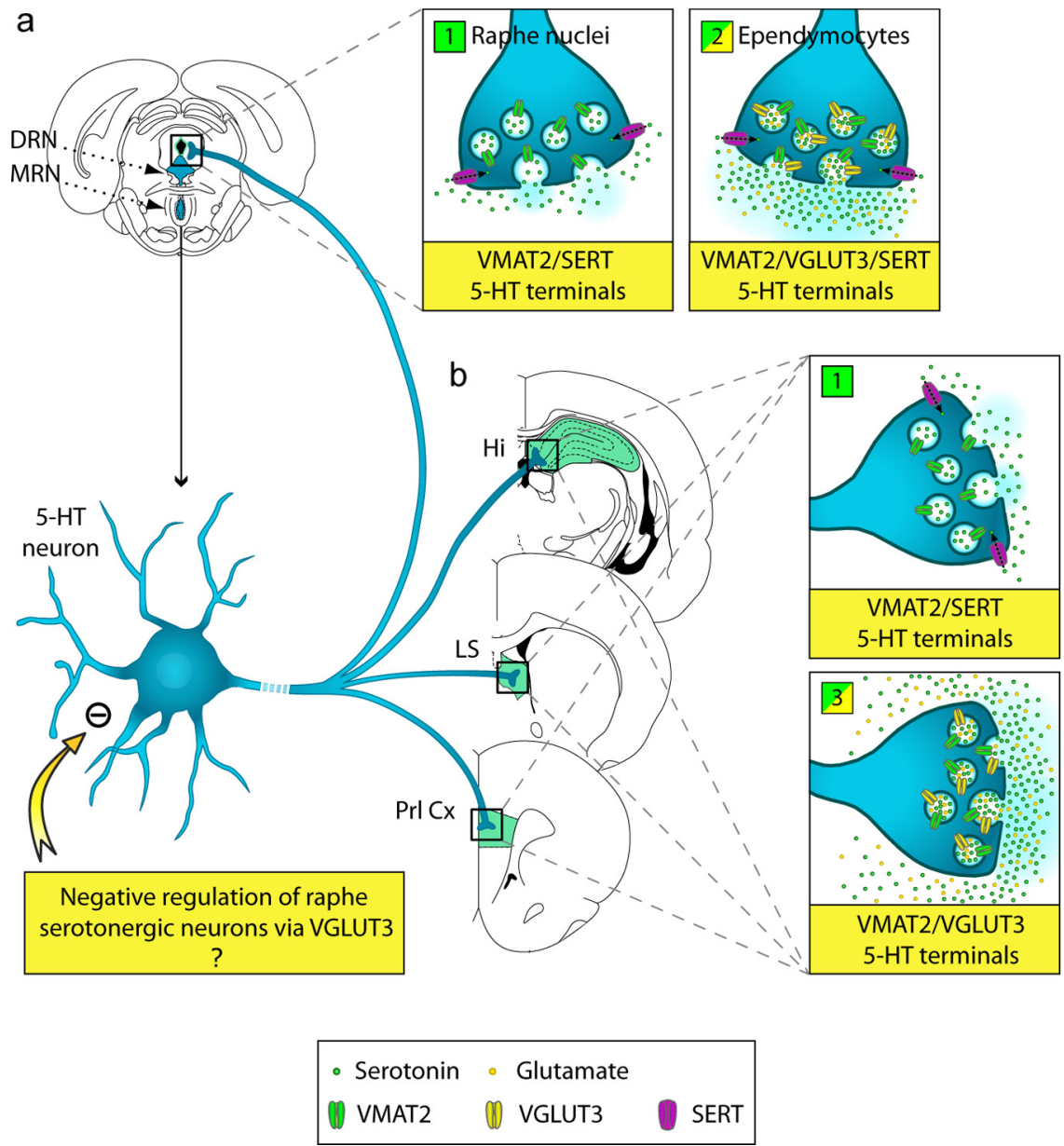

Figure 8. Schematic representation of VGLUT3 localization and functions in 5-HT neurons. a, A majority of 5-HT neurons from the DRN and MRN express VGLUT3 mRNA. In these nuclei, serotonergic terminals generally lack VGLUT3 (type 1, VMAT2/SERT 5-HT terminals). Intracellular $5 \mathrm{HT}$ is thus loaded in synaptic vesicles by VMAT2, and released in the synaptic cleft by exocytosis. 5-HT transmission is stopped 列 列

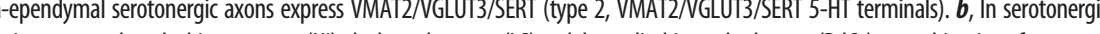
of 5-HT terminals is found in equivalent proportions. "Classical" 5 -HT terminals (type 1) coexist with 5-HT terminals expressing VGLUT3 and lacking the plasma membrane transporter SERT (type 3, VMAT2NGLUT3 5-HT terminals). Vesicular glutamate uptake via VGLUT3 allows vesicular-filling synergy thus increasing serotonergic release. Moreover, these VGLUT3-positive 5HT terminals lack SERT further strengthexing the extent and duration of 5 - $\mathrm{HT}$ transmission. Whether glutamate released by these terminals bind to presynaptic or postsynaptic different intensity of serotonergic transmission. These three types of 5-HT terminals thus allow a scaling of 5-HT transmission with Type $1<$ Type $2<$ Type 3 terminals in terms of signal intensity.

tal or pathological conditions. For example, following stressful condition, VGLUT3 could be more extensively expressed in subpopulations of 5-HT terminals where serotonergic output is more greatly demanded.

\section{Behavioral and physiological consequences of VGLUT3 ablation}

Serotonergic transmission modulates a wide range of neuronal and physiological processes (anxiety, mood regulation, impulsivity, aggressive behavior, pain perception, sleep-wake cycle, appetite, body temperature, sexual behavior). No significant change in aggression and depression-like behaviors was found in VGLUT3 knock-out mice. In contrast, the loss of VGLUT3 resulted in a specific anxiety-related phenotype. Indeed, $V g l u t 3^{-1-}$ adult mice tested in different conflict-based paradigms exhibited marked 
neophobia toward anxiogenic contexts or objects. High level of stress-induced ultrasonic vocalizations by 8 -d-old pups indicates an enhancement of innate fear (Fish et al., 2000), thus implying that the anxiety-related phenotype appears very early in the development of gglut $^{-1-}$ mice. At this age, VGLUT3 is abundant in 5-HT neurons and only poorly expressed in GABAergic interneurons from the cortex and hippocampus (see, for example, Boulland et al., 2004; Gras et al., 2005). Changes in 5-HT neurotransmission in the forebrain early during development are enough to trigger behavioral deficits in adulthood (Gross and Hen, 2004). Interestingly, reduction of 5-HT levels consecutive to PCPA treatment abolished this anxiety phenotype of Vglut $^{-1-}$ mice in the NSF test. It is thus tempting to conclude that VGLUT3 interferes with anxiety by modulating 5-HT transmission. Yet, numerous neurotransmitters have been implied in the regulation of anxiety levels, in particular the GABAergic system that partially expresses VGLUT3. Therefore, although the serotonergic hypothesis is favored here to explain the anxious profile of $V$ glut $3^{-1-}$ mice, further studies are needed to fully explain their behavioral phenotype.

In conclusion, data presented here identify a new level of complexity in the regulation of serotonergic neurons and terminals. Our observations strongly indicate that VGLUT3 plays multiple roles in the serotonergic system and suggest that it is a likely candidate gene in vulnerability to anxiety disorders.

\section{References}

Bill DJ, Knight M, Forster EA, Fletcher A (1991) Direct evidence for an important species difference in the mechanism of 8-OH-DPAT-induced hypothermia. Br J Pharmacol 103:1857-1864.

Boulland JL, Qureshi T, Seal RP, Rafiki A, Gundersen V, Bergersen LH, Fremeau RT Jr, Edwards RH, Storm-Mathisen J, Chaudhry FA (2004) Expression of the vesicular glutamate transporters during development indicates the widespread corelease of multiple neurotransmitters. J Comp Neurol 480:264-280.

Branchi I, Santucci D, Alleva E (2001) Ultrasonic vocalisation emitted by infant rodents: a tool for assessment of neurobehavioural development. Behav Brain Res 125:49-56.

Brown P, Molliver ME (2000) Dual serotonin (5-HT) projections to the nucleus accumbens core and shell: relation of the 5-HT transporter to amphetamine-induced neurotoxicity. J Neurosci 20:1952-1963.

Caliendo G, Santagada V, Perissutti E, Fiorino F (2005) Derivatives as 5HT1A receptor ligands-past and present. Curr Med Chem 12:17211753.

Cheng L, Chen CL, Luo P, Tan M, Qiu M, Johnson R, Ma Q (2003) Lmxlb, Pet-1, and Nkx2.2 coordinately specify serotonergic neurotransmitter phenotype. J Neurosci 23:9961-9967.

Commons KG, Valentino RJ (2002) Cellular basis for the effects of substance $\mathrm{P}$ in the periaqueductal gray and dorsal raphe nucleus. J Comp Neurol 447:82-97.

Dahlstroem A, Fuxe K (1964) Evidence for the existence of monoamine containing neurons in the central nervous system. I. Demonstration of monoamines in the cell bodies of brainstem neurons. Acta Physiol Scand Suppl 232:1-55

Danbolt NC (2001) Glutamate uptake. Prog Neurobiol 65:1-105.

Descarries L, Mechawar N (2000) Ultrastructural evidence for diffuse transmission by monoamine and acetylcholine neurons of the central nervous system. Prog Brain Res 125:27-47.

Fish EW, Sekinda M, Ferrari PF, Dirks A, Miczek KA (2000) Distress vocalizations in maternally separated mouse pups: modulation via 5-HT(1A), 5-HT(1B) and GABA(A) receptors. Psychopharmacology (Berl) 149: 277-285.

Fletcher A, Forster EA, Bill DJ, Brown G, Cliffe IA, Hartley JE, Jones DE, McLenachan A, Stanhope KJ, Critchley DJ, Childs KJ, Middlefell VC, Lanfumey L, Corradetti R, Laporte AM, Gozlan H, Hamon M, Dourish CT (1996) Electrophysiological, biochemical, neurohormonal and behavioural studies with WAY-100635, a potent, selective and silent 5-HT1A receptor antagonist. Behav Brain Res 73:337-353.

Fremeau RT Jr, Burman J, Qureshi T, Tran CH, Proctor J, Johnson J, Zhang
H, Sulzer D, Copenhagen DR, Storm-Mathisen J, Reimer RJ, Chaudhry FA, Edwards RH (2002) The identification of vesicular glutamate transporter 3 suggests novel modes of signaling by glutamate. Proc Natl Acad Sci U S A 99:14488-14493.

Froger N, Gardier AM, Moratalla R, Alberti I, Lena I, Boni C, De Felipe C, Rupniak NM, Hunt SP, Jacquot C, Hamon M, Lanfumey L (2001) 5-hydroxytryptamine (5-HT)1A autoreceptor adaptive changes in substance $\mathrm{P}$ (neurokinin 1) receptor knock-out mice mimic antidepressantinduced desensitization. J Neurosci 21:8188-8197.

Gasnier B (2000) The loading of neurotransmitters into synaptic vesicles. Biochimie 82:327-337.

Gaspar P, Cases O, Maroteaux L (2003) The developmental role of serotonin: news from mouse molecular genetics. Nat Rev Neurosci 4:1002-1012.

Gervasoni D, Peyron C, Rampon C, Barbagli B, Chouvet G, Urbain N, Fort P, Luppi PH (2000) Role and origin of the GABAergic innervation of dorsal raphe serotonergic neurons. J Neurosci 20:4217-4225.

Gingrich JA, Hen R (2001) Dissecting the role of the serotonin system in neuropsychiatric disorders using knockout mice. Psychopharmacology (Berl) 155:1-10.

Goodwin GM, De Souza RJ, Green AR (1985) Presynaptic serotonin receptor-mediated response in mice attenuated by antidepressant drugs and electroconvulsive shock. Nature 317:531-533.

Gras C, Herzog E, Bellenchi GC, Bernard V, Ravassard P, Pohl M, Gasnier B, Giros B, El Mestikawy S (2002) A third vesicular glutamate transporter expressed by cholinergic and serotoninergic neurons. J Neurosci 22:5442-5451.

Gras C, Vinatier J, Amilhon B, Guerci A, Christov C, Ravassard P, Giros B, El Mestikawy S (2005) Developmentally regulated expression of VGLUT3 during early post-natal life. Neuropharmacology 49:901-911.

Gras C, Amilhon B, Lepicard EM, Poirel O, Vinatier J, Herbin M, Dumas S, Tzavara ET, Wade MR, Nomikos GG, Hanoun N, Saurini F, Kemel ML, Gasnier B, Giros B, El Mestikawy S (2008) The vesicular glutamate transporter VGLUT3 synergizes striatal acetylcholine tone. Nat Neurosci 11:292-300.

Gross C, Hen R (2004) The developmental origins of anxiety. Nat Rev Neurosci 5:545-552.

Guilloux JP, David DJ, Guiard BP, Chenu F, Repérant C, Toth M, Bourin M, Gardier AM (2006) Blockade of 5-HT1A receptors by (+/-)-pindolol potentiates cortical 5-HT outflow, but not antidepressant-like activity of paroxetine: microdialysis and behavioral approaches in 5-HT1A receptor knockout mice. Neuropsychopharmacology 31:2162-2172.

Herzog E, Gilchrist J, Gras C, Muzerelle A, Ravassard P, Giros B, Gaspar P, El Mestikawy S (2004) Localization of VGLUT3, the vesicular glutamate transporter type 3, in the rat brain. Neuroscience 123:983-1002.

Hioki H, Fujiyama F, Nakamura K, Wu SX, Matsuda W, Kaneko T (2004) Chemically specific circuit composed of vesicular glutamate transporter 3 - and preprotachykinin B-producing interneurons in the rat neocortex. Cereb Cortex 14:1266-1275.

Hof PR, Young WG, Bloom FE, Belinchenko PV, Celio MR (2000) Comparative cytoarchitectonic atlas of the C57BL6 and 129 Sv mouse brains. New York: Elsevier.

Huttner WB, Schiebler W, Greengard P, De Camilli P (1983) Synapsin I (protein I), a nerve terminal-specific phosphoprotein. III. Its association with synaptic vesicles studied in a highly purified synaptic vesicle preparation. J Cell Biol 96:1374-1388.

Ishimura K, Takeuchi Y, Fujiwara K, Tominaga M, Yoshioka H, Sawada T (1988) Quantitative analysis of the distribution of serotonin-immunoreactive cell bodies in the mouse brain. Neurosci Lett 91:265-270.

Jackson J, Bland BH, Antle MC (2009) Nonserotonergic projection neurons in the midbrain raphe nuclei contain the vesicular glutamate transporter VGLUT3. Synapse 63:31-41.

Jankowski MP, Sesack SR (2004) Prefrontal cortical projections to the rat dorsal raphe nucleus: ultrastructural features and associations with serotonin and gamma-aminobutyric acid neurons. J Comp Neurol 468:518-529.

Kashani A, Betancur C, Giros B, Hirsch E, El Mestikawy S (2007) Altered expression of vesicular glutamate transporters VGLUT1 and VGLUT2 in Parkinson disease. Neurobiol Aging 28:568-578.

Kaushalya SK, Desai R, Arumugam S, Ghosh H, Balaji J, Maiti S (2008) Three-photon microscopy shows that somatic release can be a quantitatively significant component of serotonergic neurotransmission in the mammalian brain. J Neurosci Res 86:3469-3480.

Kosofsky BE, Molliver ME (1987) The serotoninergic innervation of cere- 
bral cortex: different classes of axon terminals arise from dorsal and median raphe nuclei. Synapse 1:153-168.

Lanfumey L, Pardon MC, Laaris N, Joubert C, Hanoun N, Hamon M, CohenSalmon C (1999) 5-HT1A autoreceptor desensitization by chronic ultramild stress in mice. Neuroreport 10:3369-3374.

Leonardo ED, Hen R (2008) Anxiety as a developmental disorder. Neuropsychopharmacology 33:134-140.

Lesch KP, Bengel D, Heils A, Sabol SZ, Greenberg BD, Petri S, Benjamin J, Müller CR, Hamer DH, Murphy DL (1996) Association of anxietyrelated traits with a polymorphism in the serotonin transporter gene regulatory region. Science 274:1527-1531.

Mannoury la Cour C, Boni C, Hanoun N, Lesch KP, Hamon M, Lanfumey L (2001) Functional consequences of 5-HT transporter gene disruption on 5-HT(1a) receptor-mediated regulation of dorsal raphe and hippocampal cell activity. J Neurosci 21:2178-2185.

Mendez JA, Bourque MJ, Dal Bo G, Bourdeau ML, Danik M, Williams S, Lacaille JC, Trudeau LE (2008) Developmental and target-dependent regulation of vesicular glutamate transporter expression by dopamine neurons. J Neurosci 28:6309-6318.

Molliver ME (1987) Serotonergic neuronal systems: what their anatomic organization tells us about function. J Clin Psychopharmacol 7:3S-23S.

Olivier B (2004) Serotonin and aggression. Ann N Y Acad Sci 1036: 382-392.

Owens MJ, Nemeroff CB (1998) The serotonin transporter and depression. Depress Anxiety 8 (Suppl 1):5-12.

Riad M, Watkins KC, Doucet E, Hamon M, Descarries L (2001) Agonistinduced internalization of serotonin-1a receptors in the dorsal raphe nucleus (autoreceptors) but not hippocampus (heteroreceptors). J Neurosci 21:8378-8386.

Riedel A, Westerholz S, Braun K, Edwards RH, Arendt T, Härtig W (2008) Vesicular glutamate transporter 3-immunoreactive pericellular baskets ensheath a distinct population of neurons in the lateral septum. J Chem Neuroanat 36:177-190.

Ruel J, Emery S, Nouvian R, Bersot T, Amilhon B, Van Rybroek JM, Rebillard G, Lenoir M, Eybalin M, Delprat B, Sivakumaran TA, Giros B, El Mestikawy S, Moser T, Smith RJ, Lesperance MM, Puel JL (2008) Impairment of SLC17A8 encoding vesicular glutamate transporter-3,
VGLUT3, underlies nonsyndromic deafness DFNA25 and inner hair cell dysfunction in null mice. Am J Hum Genet 83:278-292.

Schäfer MK, Varoqui H, Defamie N, Weihe E, Erickson JD (2002) Molecular cloning and functional identification of mouse vesicular glutamate transporter 3 and its expression in subsets of novel excitatory neurons. J Biol Chem 277:50734-50748.

Seal RP, Akil O, Yi E, Weber CM, Grant L, Yoo J, Clause A, Kandler K, Noebels JL, Glowatzki E, Lustig LR, Edwards RH (2008) Sensorineural deafness and seizures in mice lacking vesicular glutamate transporter 3 . Neuron 57:263-275.

Shutoh F, Ina A, Yoshida S, Konno J, Hisano S (2008) Two distinct subtypes of serotonergic fibers classified by co-expression with vesicular glutamate transporter 3 in rat forebrain. Neurosci Lett 432:132-136.

Somogyi J, Baude A, Omori Y, Shimizu H, El Mestikawy S, Fukaya M, Shigemoto R, Watanabe M, Somogyi P (2004) GABAergic basket cells expressing cholecystokinin contain vesicular glutamate transporter type 3 (VGLUT3) in their synaptic terminals in hippocampus and isocortex of the rat. Eur J Neurosci 19:552-569.

Stornetta RL, Sevigny CP, Guyenet PG (2002) Vesicular glutamate transporter DNPI/VGLUT2 mRNA is present in C1 and several other groups of brainstem catecholaminergic neurons. J Comp Neurol 444:191-206.

Takamori S, Malherbe P, Broger C, Jahn R (2002) Molecular cloning and functional characterization of human vesicular glutamate transporter 3 . EMBO Rep 3:798-803.

Valentino RJ, Bey V, Pernar L, Commons KG (2003) Substance P Acts through local circuits within the rat dorsal raphe nucleus to alter serotonergic neuronal activity. J Neurosci 23:7155-7159.

Vandermaelen CP, Aghajanian GK (1983) Electrophysiological and pharmacological characterization of serotonergic dorsal raphe neurons recorded extracellularly and intracellularly in rat brain slices. Brain Res 289:109-119.

Weisstaub NV, Zhou M, Lira A, Lambe E, González-Maeso J, Hornung JP, Sibille E, Underwood M, Itohara S, Dauer WT, Ansorge MS, Morelli E, Mann JJ, Toth M, Aghajanian G, Sealfon SC, Hen R, Gingrich JA (2006) Cortical 5-HT2A receptor signaling modulates anxiety-like behaviors in mice. Science 313:536-540. 